\title{
The Salience of Perceived Societal Conflict in Europe: A 27 Country Study on the Development of a Measure for Generalized Conflict Thinking
}

\author{
Yaël van Drunen ${ }^{1,2}$ (D) Bram Spruyt ${ }^{1} \cdot$ Filip Van Droogenbroeck $^{1}$
}

Accepted: 18 April 2021 / Published online: 22 May 2021

(c) The Author(s) 2021

\begin{abstract}
Over the last two decades, European countries have struggled with several crises (e.g., the Great Recession, the refugee crisis) which had a tremendous impact on (some) societies. Typically, these crises were accompanied by divisive public discourses that rely heavily on a sharp and moralistic us-them distinction. Especially extreme right- and left-wing parties have adopted such conflict discourses and have gained much electoral support. Against this background, this paper has two objectives. First, data from the European Quality of Life Survey from 2003 to 2016 in 27 countries are used to provide a comprehensive overview of the salience of perceived societal conflicts between seven pairs of groups between countries and across time. We find substantial differences between countries and longitudinal trend variation in the salience of perceived societal conflict. For example, in Eastern European countries more economic conflict is perceived, while in Western European countries people perceive more cultural conflict between different ethnic and religious groups. Second, multigroup confirmatory factor analyses reveal that specific perceptions of conflict are structured by an underlying general orientation, generalized conflict thinking: people's tendency to perceive society through the lens of conflict regardless of the specificity of these groups. The measure for generalized conflict thinking is metric equivalent across a large sample of countries. This demonstrates that generalized conflict thinking can be used as a social indicator for comparative research. In the conclusion we elaborate on the implications of our findings and develop a research agenda regarding generalized conflict thinking.
\end{abstract}

Keywords Societal conflict · Conflict thinking · Confirmatory factor analysis · Crosscultural measurement invariance $\cdot$ European quality of life survey

Yaël van Drunen

yael.van.drunen@vub.be

Bram Spruyt

bram.spruyt@vub.be

Filip Van Droogenbroeck

filip.van.droogenbroeck@vub.be

1 Sociology Department, Vrije Universiteit Brussel, Pleinlaan 2, 1050 Brussels, Belgium

2 Political Science Department, Institute for Management Research, Radboud University, Nijmegen, The Netherlands 


\section{Introduction}

Over the last two decades, European countries have struggled with several crises that have had a major impact on society. The economic crisis of 2008 resulted in a substantial job loss and material deprivation for many citizens (OECD, 2012). The austerity policies that followed further deepened income inequality (Markus et al., 2016). The refugee crisis of 2015 put pressure on national and European borders, sharpening political debates on immigration (Grande et al., 2019). In many countries, this specific debate was embedded in a much broader cultural backlash (Norris \& Inglehart, 2016) against progressive values concerning gender equality and equal rights for LGBTQ people (Eurobarometer, 2019). Finally, population ageing puts pressure on retirement funds and welfare systems, and has sparked a debate about intergenerational solidarity and responsibilities (European Commission, 2018). Although these crises affected European countries to varying degrees, there are almost no European countries that did not face the challenges posed by these crises. Typically, these crises are accompanied by divisive and moralistic discourses centred around sharp us-them distinctions whereby 'we' (e.g., the people, the citizens, the poor, the men, the young, the heterosexuals etc.) are pitted against 'them' (e.g., the elite, the immigrants/refugees, the rich, the women, the elderly, the LGBTQ community etc.). Although relying on such conflict frames is typically associated with so-called radical politics (Mudde, 2007; Ramiro \& Gomez, 2017), research shows that conflict frames are amongst the most popular media frames (Bartholomé et al., 2018). Conflict frames apparently find much resonance among the public at large and are therefore used by media, which in turn may heighten the public's sensitivity to these frames. Despite the presence of such conflict discourses, surprisingly little research has been conducted thus far on the perception of conflict between different societal groups among the wider public. We simply do not know how salient perceptions of societal conflict are and how these vary between European countries and across time. Moreover, when conflict discourses are applied in a wide range of contexts, pitting very different groups against each other, this raises the question whether (1) such a thing as generalized conflict thinking exists, i.e., a tendency to perceive society through the lens of conflict regardless of the specificity of these groups, that (2) can be measured and (3) used in comparative research.

This paper contributes to the literature in two ways. First, we theoretically discusses and empirically asses the salience of perceived societal conflict between seven pairs of groups. Relying on data from the European Quality of Life Survey (EQLS), covering 27 countries over the 2003-2016 period, we find substantial between country as well as over time trend variation in the salience of perceived societal conflict. These findings provide the first comprehensive picture of perceived societal conflict in Europe. Second, when developing a measure for generalized conflict thinking, that is people's tendency to perceive society through the lens of conflict regardless of the specificity of these groups, we combine several literatures studying conflict attitudes and add to a broader theoretical debate on belief systems (Converse, 1964). Empirically, we apply multi-group confirmatory factor analyses (MGCFA) to assess cross-national measurement invariance of our measure (Jöreskog, 1971). We extensively test the validity of our measure adopting various model specifications and replicate our findings across waves. The empirical results indicate that generalized conflict thinking can be measured by a one-dimensional scale in all countries which is metric invariant across a large sample of countries. This demonstrates that items tapping into perceived societal conflict are 
interesting social indicators and that our measure for generalized conflict thinking can be used for comparative research. In the conclusion, we elaborate on the implications of our findings and develop a research agenda.

\section{Theoretical Framework}

\subsection{Salience of Perceived Societal Conflict}

In this paper, we assess the degree to which individuals perceive conflict between different societal groups in their country. We refer to this as the salience of societal conflict. Although measures for perceived conflict among individuals are included in multiple surveys, such as the European Quality of Life Survey (EQLS) (see https://www.eurofound. europa.eu/), the International Social Survey Program (ISSP) (see http://www.issp.org/), the German General Social Survey ALLBUS (see https://www.gesis.org/allbus), and the Polish Panel Survey (see http://polpan.org/), relatively little research has been conducted on perceived conflict. The few studies that exist focused on single-country contexts (Janicka, 2002; Spruyt, 2014) or studied the perception of conflict in Eastern European countries by combining data from multiple surveys (Zagórski, 2006). Our aim is not restricted to providing a more comprehensive picture by mapping the salience of perceived societal conflict in 27 European countries from 2003 to 2016. We also theorize and empirically assess the existence and relevance of perceived societal conflict. To that end, it is crucial to distinguish between the salience of and preference for an issue. We borrow the distinction between salience and preference from (a) the literature on public opinion research and (b) experimental social psychology. Typically, in public opinion research, respondents are asked to express their (policy) preferences (e.g., are you pro or contra?), as well as what the subjective importance of a specific issue or topic is (e.g., what is the most important problem in your country?) (Hatton, 2017; Wlezien, 2005). In this reasoning, preference is considered to be evaluative, while salience is about cognitive awareness (Hatton, 2017). Hatton (2017) found little correspondence between preference (i.e., the attitude towards immigrants) and salience (i.e., the subjective importance of immigration as an issue) in attitudes towards immigration. Even those scholars who do argue that preference and salience are most often empirically related, consider both elements essential in understanding outcomes such as voting behaviour (Wlezien, 2005). Moreover, a long tradition exists in social psychology that experimentally manipulates the salience of issues, further substantiating the importance of this concept. These experiments are performed by creating conditions that make respondents cognitively aware of a specific issue. Time and again, these experiments have shown that the salience of issues has independent causal effects on people's behaviour (Schwartz \& Strack, 1981; Turner, 1982).

Building upon the distinction between salience and preference and applying it to the current focus of societal conflict, we argue that our notion of perceived societal conflict should be differentiated from measures of polarization. Many scholars have studied the concept of polarization, measuring ideological differences amongst political parties or citizens (Dalton, 2008). A first difference between perceived societal conflict and polarization, then, is that perceived societal conflict covers a much broader area than the political sphere. A second difference becomes clear when we focus on one of the most used measures of polarization among citizens, namely affective polarization, that is the expression of hostile feelings towards groups with opposing political identities (Gidron et al., 2019; 
Iyengar et al., 2012; Mason, 2016). Affective polarization is usually measured using a thermometer scale to express negative or positive feelings towards opposing groups (Reiljan, 2020; Wagner, 2020). Such a measure focuses on preferences and taps into the emotional evaluation of outgroups (e.g., dislike people with opposing political identities). In contrast, perceived societal conflict reflects the salience of societal conflict, the degree to which individuals are cognitively aware of certain conflicts in society.

The salience of perceived societal conflict is likely to be influenced by contextual-level factors. Party discourses and media affect how people think about certain issues and set the agenda on which issues become salient (Kiousis \& McCombs, 2004). Therefore, we expect to find substantial cross-country and longitudinal trend variation in the overall salience of perceived societal conflict between different pairs of groups. Cross-country differences will result from the supply side of politics. We know for example, that (rightist and leftist) populist parties rely heavily on conflict discourses to rally electoral support (Mudde, 2004). Moreover, higher levels of party polarization (Dalton, 2008) may increase the level of perceived societal conflict amongst individuals. Besides, cross-country variation in the salience of perceived societal conflicts may relate to historical factors such as country-specific cleavage structures (Kriesi et al., 2008; Lipset \& Rokkan, 1967) or the communist legacy in Central and Eastern European countries (Kitschelt, 1995; Rohrschneider \& Whitefield, 2009). Trends in perceived conflicts are expected to relate to societal events that had a severe impact on countries such as the Great Recession and the refugee crisis of 2015. Our goal here is not to assess the relationship between such contextual factors and the perception of societal conflict. Nevertheless, capturing this variation could be seen as supporting evidence for the external validity of the items measuring perceived societal conflict.

\subsection{Generalized Conflict Thinking}

Besides assessing and comparing the salience of perceived societal conflict between specific pairs of groups, we also study the interrelations between the items that refer to specific conflicts. Previous research revealed positive correlations between items contributing to perceived conflict between diverse societal groups. This observation prompted Spruyt et al. (2018) to argue that specific perceptions of conflict partly result from a more general tendency to perceive the world through the lens of conflict, regardless of the specificity of the groups involved. They referred to this tendency as generalized conflict thinking and argued that adopting such a perception scheme may fulfil socio-psychological needs. Below we briefly discuss why the existence of such generalized conflict thinking is plausible and subsequently explain how this study improves upon Spruyt et al. (2018).

A first reason why some people may be inclined to perceive the world through the lens of societal conflict follows from the observation that conflict frames abound in public discourse. Conflict frames "put emphasis on conflict between individuals, groups or institutions to capture the audience interest" (Semetko \& Valkenburg, 2000 p. 95) and are highly prevalent in news coverage, especially when reporting political news (Semetko \& Valkenburg, 2000). Journalists have been found to play an active role in the creation of such conflict frames by "exaggerating language and amplifying possible consequences of political conflict" (Bartholomé et al., 2015 p. 439). Moreover, the concept of media populism reveals how some media express ideological elements of populism, criticising the elites and claiming to speak for the people, thereby contributing to the construction of in- and out-groups (Krämer, 2014). These type of frames are attractive and likely to resonate among the public as they structure political debate thereby offering clear sides between 
groups (Semetko \& Valkenburg, 2000). This tendency in journalism is complemented by a change in politics. In recent years, 'cultural' politics - the focus on issues such as immigration, law and order, progressive ethics, etc.Mudde, 2007). Typical for these issues is that they easily become moralistic and are discussed in terms of good and bad. Such issues, in short, lend themselves to be framed in terms of conflict. Moreover, populist parties have gained electoral support across Europe, albeit to different degrees. The 'corrupt elite' are pitted against the 'common people' in populist rhetoric, expressing a Manichean worldview where politics is essentially a struggle between good and evil (Hawkins \& Rovira Kaltwasser, 2018; Mudde, 2004). Although mainstream parties vary substantially in the degree to which they adopt a populist rhetoric (Rooduijn et al., 2014), the electoral success of populist parties shows that conflict discourses resonate with the public. The preceding arguments all support the idea that there is a great 'supply-side' of conflict frames in contemporary (Western) societies and this may have an impact on how citizens view their own society. The question remains, however, why specific perceptions of societal conflict are likely to be underpinned by a more general tendency to perceive conflict in society to a greater or lesser extent. To answer this question, we rely upon the concept of belief systems (Converse, 1964) and bring together different bodies of literature that hint at the existence of such a general tendency to perceive conflict in society. Accordingly, we argue that beside a 'supply side' for conflict thinking there is also a 'demand side'.

The literature on belief systems holds that individuals understand and structure politics according to their belief system, understood as 'a configuration of ideas and attitudes in which elements are bound together by some form of constraint or functional interdependence' (Converse, 1964, p. 3). A belief system thus clusters specific attitudes that are guided by a more general orientation (i.e., constraint). Scholars have identified different sources of constraint, such as partisanship and political sophistication (Converse, 1964; Lipset, 1967). More recent work on belief systems shows indeed that people structure their political attitudes in certain belief systems (Baldassarri \& Goldberg, 2014; Daenekindt et al., 2017; Goldberg, 2011). Daenekindt et al. (2017) furthermore show that individuals who share the same belief system (i.e., similar relationships between their attitudes) do not necessarily have the same (cultural) attitudes. Belief systems are not about how individuals position themselves on certain issues but instead follow from, a certain logic, that binds the composing views (Goldberg, 2011). Here, we argue that generalized conflict thinking functions as such a constraint that connects specific perceptions of societal conflict.

To further illustrate the reasoning behind the idea of generalized conflict thinking, we provide two well-known examples that illustrate that perceptions of specific conflicts tend to cluster, namely (generalized) prejudice and populism. First, the literature on (generalized) prejudice has consistently shown that individuals who express prejudice towards one group are strongly inclined to do so towards another group (Akrami et al., 2011; Ekehammar et al., 2004; Kalkan et al., 2009; Zick et al., 2008). Second, an element of conflict thinking is also strongly present in populism. As explained earlier, central to the ideational approach to populism is a Manichean worldview that represents politics as a struggle between two homogenous and antagonistic groups, namely the 'pure people' and 'the corrupt elite' (Hawkins \& Kaltwasser, 2018; Mudde, 2004). These categories of 'the pure people' and 'the corrupt elite', however, have no independent meaning. They are what is known as 'empty signifiers' and their meaning is fully determined by their antagonistic relationship - 'the people' are everything that 'the elite' is not and vice versa (Laclau, 2005). It is exactly that property that enables populism to unite different grievances in the electorate. In this way, populism aligns with a more general disposition that reduces society 
to 'us' versus 'them' (Rooduijn, 2019 p. 368). From a theoretical perspective, it can thus be argued that populism is part and parcel of a more general orientation that drives people to perceive varying degrees of societal conflict overall and not just between 'the people' and 'the elite'.

Although the examples of generalized prejudice and populism, help us to understand the logic behind generalized conflict thinking, there is also an important difference. Indeed, whereas generalized prejudice, populism, but also the earlier discussed (affective) polarization, all refer to preferences, generalized conflict thinking reflects the salience of societal conflicts. Although individuals who score high on affective polarization, populism or (generalized) prejudice are likely to perceive high levels of societal conflict, the reverse may not be necessarily true. The relation between salience and preference can be asymmetric. It is possible that people perceive a certain conflict to be salient in society, but not feel as if they prefer one of the groups involved in the conflict. Moreover, people may strongly differ in terms of the specific groups they prefer, but agree on the level of perceived conflict between two groups. In our reasoning, generalized conflict thinking can only function as a constraining factor precisely because it is not about an individual's personal preference in certain conflicts but rather refers to the societal salience of these conflicts. People on opposing sides of a conflict can grant similar scores to the salience of that conflict. Interpreting generalized conflict thinking as a certain logic allows us to integrate perceptions of conflict between a variety of societal groups: rich-poor people, managers-workers, men-women, young-old people, people with different ethnic backgrounds, people from different religious groups and people with different sexual orientations. This reveals another distinguishing characteristic of generalized conflict thinking. Indeed, while measures of (generalized) prejudice, populism and affective polarization exclusively focus on specific groups (i.e. ethnic groups, elites and political outgroups) our measure of generalized conflict thinking takes a broader perspective and enables us to get a more comprehensive understanding of conflict dynamics in society, moving beyond political preferences. Earlier work on the amount of perceived conflict provided tentative support for the idea that generalized conflict thinking can be measured by a one-dimensional scale (Spruyt et al., 2018). Here, we build upon this work by (1) testing these measurement models based on more recent data from more countries and (2) by assessing cross-cultural measurement invariance (Davidov et al., 2014).

\section{Data and Methods}

\subsection{Data Source}

We rely on data from four waves of the European Quality of Life Survey (EQLS). The EQLS is (1) a cross-country data set that (2) includes the broadest range of items tapping into perceived societal conflicts. The conflict items included in other comparative surveys like the International Social Survey Programme (ISSP) focus narrowly on economic groups (poor and rich people, working-class and middle class, managers and workers), and thus do not allow for adequate measurement of generalized conflict thinking. Other surveys, such as the German ALLBUS or the Polish Panel Survey, include many items that measure perceived societal conflict between a range of groups but are single-country studies.

We use data from all four waves - 2003, 2007, 2011 and 2016 - of the EQLS. The survey covers approximately 30 countries. We excluded the following countries as they did 
not participate in all waves: Albania, Croatia, FYR of Macedonia, Iceland, Kosovo, Montenegro, Norway and Serbia. We also removed Turkey from the analyses as this is the only non-EU country. This sets the number of countries in our analyses to 27 . The full technical report, including details on the fieldwork and country-specific response rates, can be found on www.eurofound.europa.eu.

\subsection{Measures}

The amount of perceived societal conflict between pairs of groups, our dependent variable, was measured by the question: "In all countries there sometimes exists tension between social groups. In your opinion, how much tension is there between each of the following groups in this country?" Respondents were asked to indicate whether they saw (1) a lot, (2) some or (3) no tension for seven pairs of groups: poor and rich people, managers and workers, men and women, old people and young people, different ethnic groups, different religious groups and people with different sexual orientations. We include pairs of groups for which there is no immediate substantive reason to expect strong inter-item correlations (e.g., women and men vs. poor and rich people). An empirical correlation between such items is in itself likely to reflect conflict thinking. Indeed, it is the diversity of groups that will guarantee the content validity of our proposed measure for generalized conflict thinking.

\subsection{Methods}

To assess scale properties and measurement invariance across countries we performed multi-group confirmatory factor analyses (MGCFA) (Jöreskog, 1971). Since we have an ordinal variable, the models are estimated through a diagonally weighted least squares estimation method (DWLS) in R, using the lavaan package (Rosseel, 2012). The model fit was assessed by relying on the most recommended goodness-of-fit-statistics and related cutoff values: RMSEA <0.08, CFI and TLI > 0.95, and SRMR < 0.06 (Hu \& Bentler, 1999). Much discussion remains regarding the relative cut-off values for model comparisons. Here, we use the cut-off values recommended by Chen (2007) and Cheung and Rensvold (2002). As others rely on less restrictive cut-off values, the most important consideration here is that, even though fit indices help to evaluate model fit, they should not overrule substantive judgment (Chen, 2007 p. 502).

An important objective of this paper is to assess whether conflict thinking can be measured comparatively. Following the literature on measurement invariance (Byrne et al., 1989; Davidov et al., 2014; Meredith, 1993; Putnick \& Bornstein, 2016; Steenkamp \& Baumgartner, 1998; van de Schoot et al., 2012), we distinguish between three hierarchical levels of measurement invariance: configural, metric and scalar invariance.

Configural invariance entails that the latent variable is defined in the same way across countries. Second, metric invariance constraints the factor loadings to be equal so that one united increase on the measurement scale has the same meaning across countries. A metric invariant measure implies that unstandardized regression coefficients and covariances can be compared across countries. Statistically, metric invariance is maintained when there is an increase in RMSEA of $\leq 0.015$, in SRMR of $\leq 0.030$, supplemented by a change in CFI or TLI of $\leq 0.010$ (Chen, 2007; Cheung \& Rensvold, 2002) compared to the configural model. Third, scalar invariance constraints both the factor loadings and the intercepts to being equal and implies that the mean of the latent variable can be compared across 
countries. We compare the fit indices of the scale model with the metric model. For scalar invariance, the cut-off criteria for the RMSEA and CFI and TLI remain the same, but for SRMR it is $\leq 0.010$ (Chen, 2007; Cheung \& Rensvold, 2002). In practice, higher levels of invariance are often not met for commonly used scales such as social trust (Reeskens \& Hooghe, 2007), political efficacy (Saris \& Gallhofer, 2012) or populist attitudes (Castanho Silva et al., 2020). Since the requirements for full measurement invariance might be too strict, especially when having a large number of countries (Steinmetz et al., 2009 p. 604), we subsequently test for partial measurement invariance where we allow some parameters to vary across groups (Byrne et al., 1989). Following Steenkamp and Baumgartner (1998), partial measurement invariance holds when at least two factor loadings/intercepts are constrained to be equal across groups.

\section{Results}

\subsection{Cross-Country and Longitudinal Trend Variations in the Perception of Societal Conflict}

The past two decennia have been a turbulent time for European citizens. Europe struggled with different crises and many challenges remain. Public debates on all of this have been fuelled by the rise of increasingly extreme right- and left-wing parties. Is this reflected in European citizens' perceptions of societal conflict? We present descriptive figures ${ }^{1}$ below that offer a unique and comprehensive overview of the perception of societal conflict in Europe. Figure 1 shows the percentage of people that indicated to perceive 'a lot of tension' between each of the seven pairs of groups, and the mean score of perceived societal conflict for each country in the period 2003-2016. ${ }^{2}$ Four observations can be made.

First, we find substantial cross-country variation regarding the level of perceived societal conflict in Europe. For example, economic conflict is much less expressed in countries with a strong welfare system, such as Denmark, where on average less than $5.0 \%$ of the people indicated perceiving a lot of conflict between poor and rich people and managers and workers, compared to over $55.0 \%$ of the people in Hungary. This cross-country variation is not only expressed for typical economic conflicts, but also for cultural conflicts. In Latvia, $7.0 \%$ of the people perceive a lot of conflict between different religious groups, while this is over $40.0 \%$ in France. Perceived conflict between men and women ranges from $4.0 \%$ in Denmark to $16.6 \%$ in Romania, and only $7.2 \%$ of the people in Denmark perceive a lot of tension between groups of people with different sexual orientations, while $36.9 \%$ of the people in Lithuania indicate perceiving a lot of conflict between these groups.

Second, countries also vary in terms of how groups are ordered regarding the salience of perceived conflict. In general, European citizens (Fig. 2) perceive the most conflict between different ethnic groups (perceived to be highest in 16 countries), followed by poor and rich people (highest in 8 countries) and managers and workers (highest in 2 countries). Modest levels of conflict are perceived between people from different religious groups and people

\footnotetext{
${ }^{1}$ Corresponding tables of the figures can be found in the online "Appendix".

2 The mean score functions as a reference category within countries. To compare the mean score between the waves in a meaningful way, only those items that are present in every wave were included. This excludes the items 'perceived conflict between different religious groups' and 'perceived conflict between people with different sexual orientations'.
} 


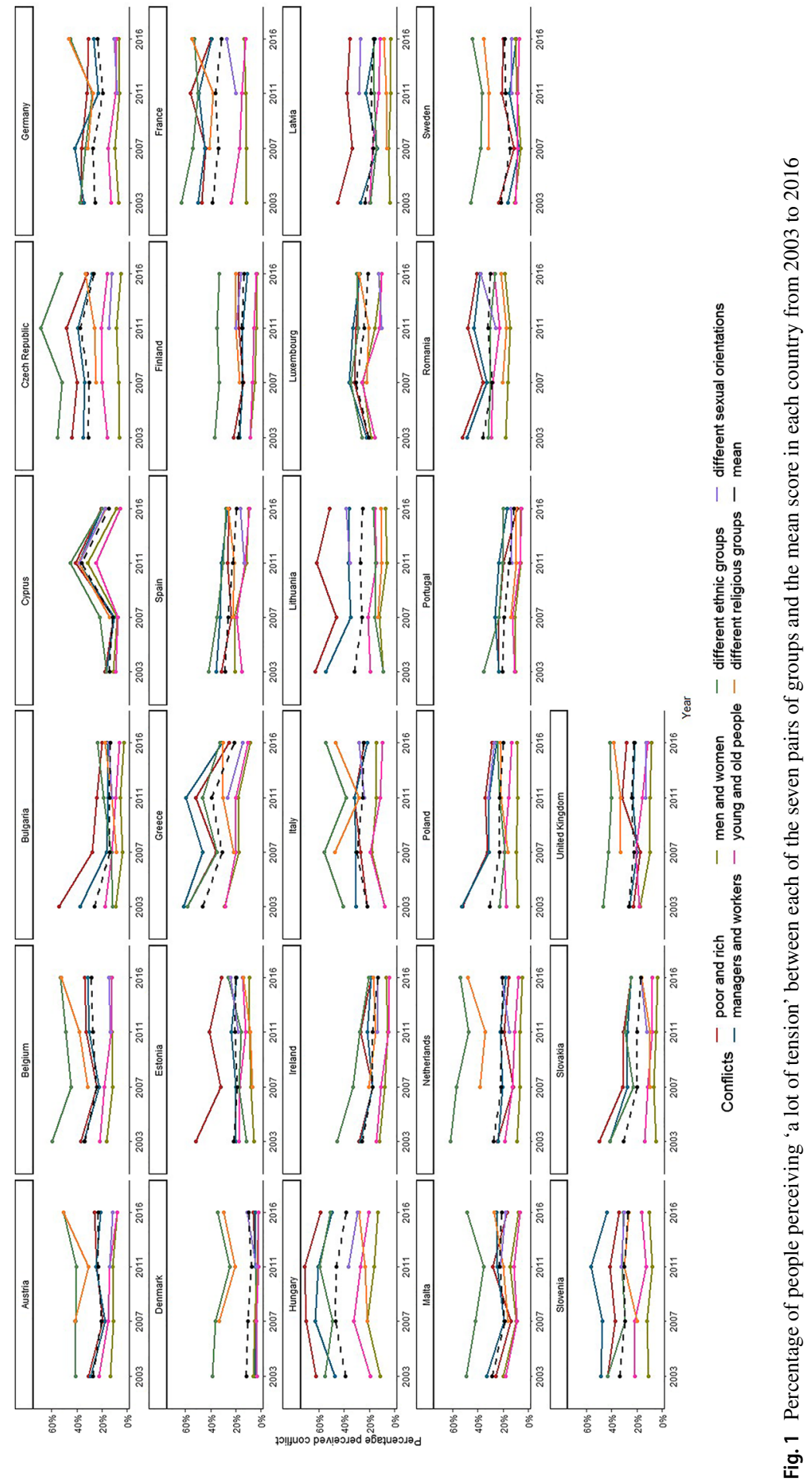



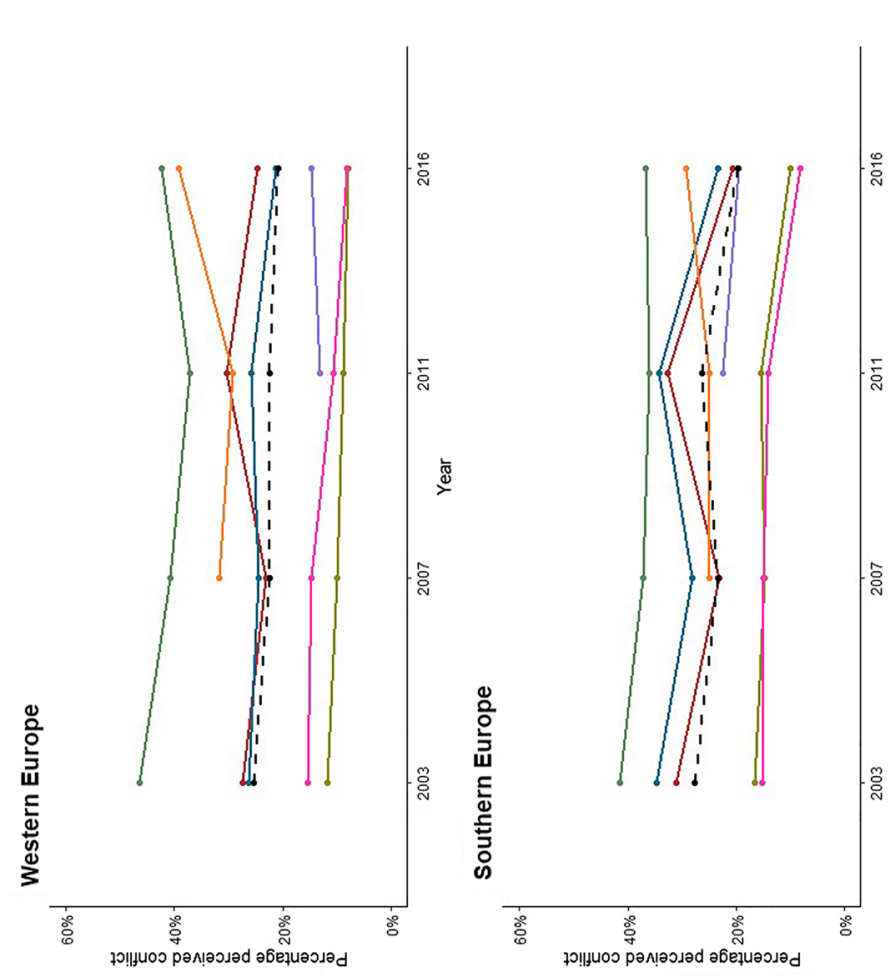

हี

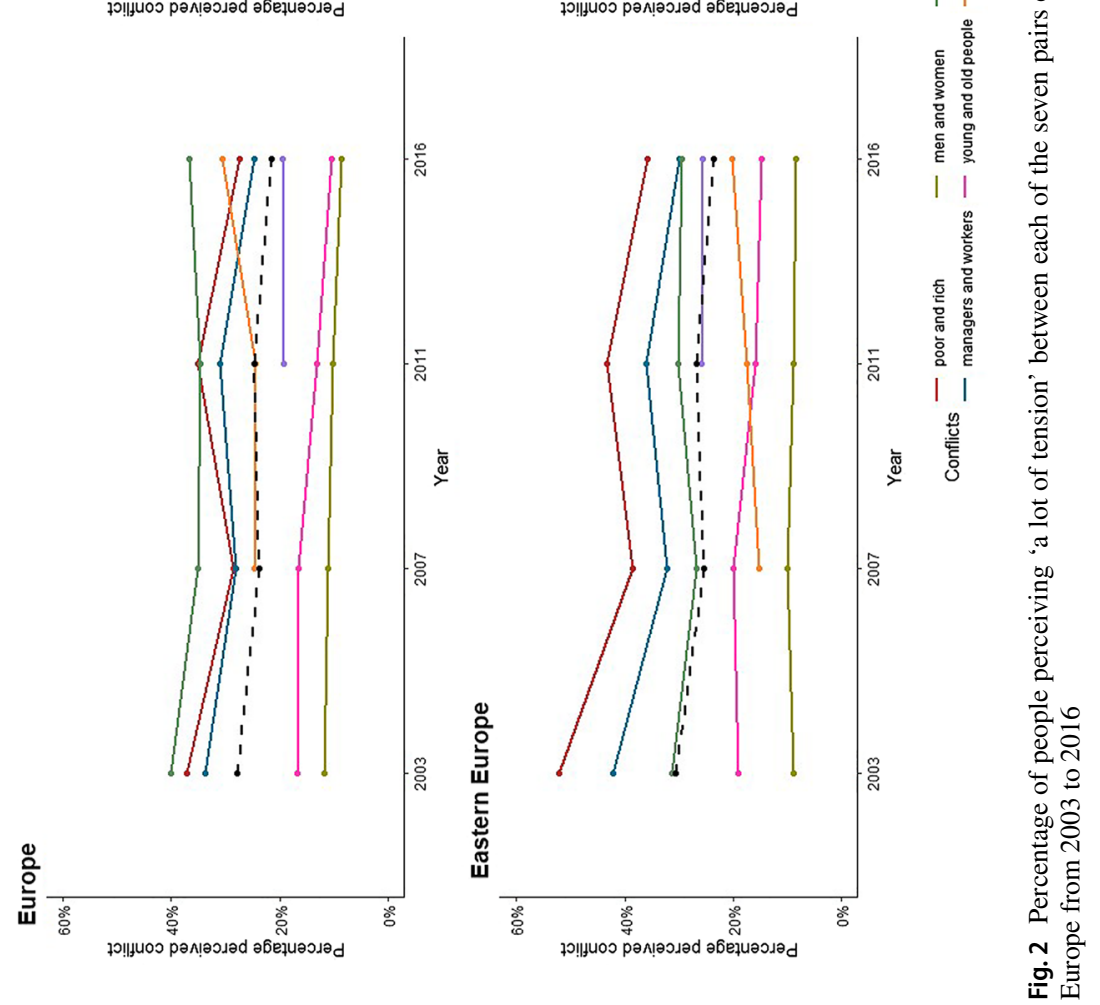


with different sexual orientations. The lowest levels of conflict are perceived between men and women and young and old people. There are, however, clear regional variations on that general pattern. We classified the countries into three regions: (1) Western Europe, including Austria, Belgium, Germany, Denmark, Finland, France, Ireland, Luxembourg, The Netherlands, Sweden and The United Kingdom, (2) Eastern Europe, including Bulgaria, the Czech Republic, Estonia, Hungary, Lithuania, Latvia, Poland, Romania, Slovenia and Slovakia and (3) Southern Europe, including Cyprus, Greece, Spain, Italy, Malta and Portugal (Fig. 2). In Western Europe perceived conflict between different ethnic groups and religious groups is highest, while in Eastern Europe the level of perceived conflict between the poor and the rich and managers and workers is much higher. In Southern Europe, perceived conflict between different ethnic groups is highest, but more closely followed by perceived economic conflict — as expressed by the poor vs. the rich, and managers vs. workers - than in Western Europe. Moreover, people in Southern and Eastern European countries perceive a lot more conflict between people with different sexual orientations than people in Western Europe do. Some countries, however, do not follow this regional pattern. In the Czech Republic (Eastern Europe), conflict between different ethnic groups is perceived to be about 10-20\% higher than conflict between the poor and the rich and managers and workers. In Luxembourg (Western Europe) and Portugal (Southern Europe), people perceived more conflict between managers and workers than between different ethnic groups in 2007 and 2011. This was also the case for the Western European countries Germany and France, where perceived conflict between poor and rich was highest in 2011. These examples illustrate that the items reflect country-specific and region-specific variation. Furthermore, they also demonstrate that while there are regional patterns, countries still vary within their own region. Therefore, it is evident that one must look at individual countries and make country-level comparisons.

Third, the figures also reflect longitudinal trend variation in the level of perceived societal conflict. From 2007 to 2011, we see an increase in perceived conflict in most countries between poor and rich people and managers and workers. This makes sense as this was also the period of the Great Recession. The latter interpretation is further supported by the finding that the increase in perceived economic conflicts was highest in Greece and Cyprus, two countries that were severely hit by the economic crisis. Between 2011 and 2016, perceived conflict between economic groups generally declined and we observe an increase in perceived conflict between different ethnic groups and religious groups. This may be related to the refugee crisis of 2015 and the subsequent success of far-right parties in many European countries. Moreover, this increase is especially pronounced in Austria, Belgium, Germany, Denmark, France, Italy, the Netherlands, Sweden and the United Kingdom, countries with strong populist radical right parties that gained support by setting immigration high on the political agenda. Although more research is needed to test the relationships between these events and the level of perceived conflict among the public at large, the different examples strongly suggest that such relationships are plausible and that the conflict perceptions are interesting social indicators.

Fourth, regarding the within-country variation between individual items, we see that the percentage of perceived conflict varies between different societal groups. Depending on the context, people perceive much more conflict between certain pairs of groups than others. For example, there are relatively low levels of perceived economic conflict and conflict between people with different sexual orientations in Austria, Denmark, Finland, The Netherlands and Sweden, but the level of perceived conflict between different ethnic groups and different religious groups is relatively high in these countries. Nevertheless, while the individual items vary substantially within countries, there is a synergy between 
the seven items. Looking at Greece and Cyprus again, there is a sharp increase in perceived conflict between all seven pairs of groups in the period from 2007 to 2011. After 2011, we notice a sharp decrease in perceived conflict between all pairs of groups. This pattern of simultaneously increasing/decreasing within-country levels of perceived conflict between different pairs of groups appears in almost all countries to varying degrees. This observation suggests that the perceived societal conflict between a specific pair of groups is at least partially determined by a more general tendency to perceive societal conflict. Indeed, the average correlation between the seven pairs of groups equals 0.39 (range 0.30-0.65). We find strong correlations for perceived economic conflict between poor and rich people and managers and workers $(0.51<$ Pearson's $r>0.54)$, and cultural conflict between different ethnic groups and religious groups $(0.58<$ Pearson's $r>0.65)$. These four observations lead to two conclusions that are crucial to our next purpose. First, the items capture both crosscountry as well as longitudinal trend variation of perceived conflict between seven pairs of groups. Although we did not test it formally, clearly this variation also mirrors societal crises and major events in Europe. The latter observation can be seen as evidence supporting the external content validity of the items that we use here. Second, the correlations between the items suggest that people who perceive conflict between one pair of groups are likely to perceive conflict between other pairs of groups, supporting our argument for the existence of generalized conflict thinking. In what follows, we specify a measurement model for generalized conflict thinking and assess cross-country measurement invariance.

\subsection{Specification of the Measurement Model}

We first build a measurement model for generalized conflict thinking for the most recent (2016) wave and subsequently replicate this model for the 2011 and 2007 waves to test the robustness of our results. ${ }^{3}$ In the first step, we estimated confirmatory factor analyses (CFA) for each country separately whereby all seven items loaded on one latent factori.e., generalized conflict thinking. This measurement model does not indicate a good fit in almost all countries for all waves. Adding two error-covariances between item 1 (poor and rich people) and item 2 (managers and workers) and item 5 (different ethnic groups) and 6 (different religious groups) (see Fig. 3) significantly improved the fit. Theoretically, the first two items refer to the economic dimension, capturing typical class conflicts, while items 5 and 6 refer to more cultural conflict. Empirically, these items show the highest modification indices ${ }^{4}$ (Kline, 2011). Together, both elements justify the specification of these two error covariances.

When tested on the 2016 wave, this model showed a good fit in 24 countries, except in the Czech Republic, Poland and Slovakia. For the Czech Republic, RMSEA is 0.085, for Poland RMSEA is 0.097 and SRMR is 0.063 , and for Slovakia, RMSEA is 0.128, CFI is 0.948 and TLI is 0.908 and SRMR is 0.083 , most slightly exceeding the respective cut-off values. An overview of all fit statistics per country per wave can be found in the online "Appendix".

A replication of the analyses on the 2011 and 2007 waves shows that 22 countries have a good fit for the 2011 wave, except for Bulgaria, Estonia, Latvia, Romania and Slovenia.

\footnotetext{
${ }^{3}$ Robustness of the results was not checked on the 2003 wave, since both item 7: conflict between different sexual orientations and item 5: conflict between different ethnic groups, were not present in this wave.

4891.551 for item $1-2$ and 1873.083 for item 5-6 on the pooled data for 2016.
} 


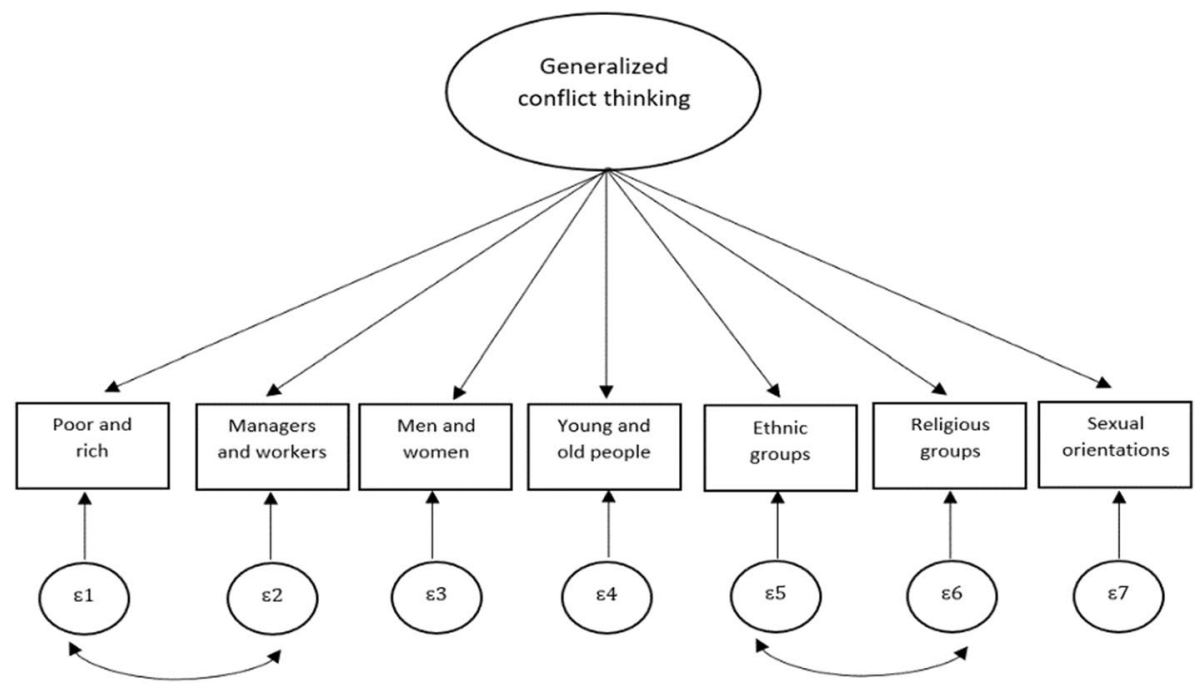

Fig. 3 Measurement model

Slovenia shows the worst fit, with an RMSEA of 0.104, CFI of 0.944 , TLI of 0.903 and SRMR of 0.069 . For the 2007 wave, we specify our model using only six items because item 7 - i.e., conflict between people with different sexual orientations — was not included in the questionnaire. The measurement model indicates a good fit in all 27 countries. This suggests that item 7 contributes significantly to the bad fit in Eastern European countries for the 2011 and 2016 wave. This makes sense, as research shows that the acceptance of equal rights for LGBTQ people is less than 50\% in most Eastern European countries, whereas in Western European countries this is close to $80 \%$ or higher (Eurobarometer, 2019). Moreover, as shown in Fig. 2, perceived conflict between people with different sexual orientations is much higher in Eastern Europe than in Western Europe. Therefore, we ran an additional analysis where we excluded item 7 from the 2016 and 2011 waves. This leads to a significant improvement of the model fit; all countries now demonstrate a good fit, except Greece in 2016, where the RMSEA remains too high (RMSEA =0.093).

Taken together, these findings provide support for the idea that in most countries, perceived conflict between diverse pairs of groups is structured by an underlying latent concept of generalized conflict thinking. Although we identified a few countries where the measurement model does not have a good fit, back testing by replicating the measurement model on earlier waves suggest that some of these deviations may be due to randomness and/or sampling. Indeed, we found no countries that consistently indicate a bad fit on all waves. That said, we found interesting patterns on a lower level and especially the item concerning groups who differ in sexual orientation (item 7) seems to work differently in Eastern vs. Western European countries. We continue to include this item 7 in further equivalence testing to study this effect in more detail. Countries with a bad fit are left out of the measurement invariance tests for that wave. This strategy enables us to perform a conservative test to ensure that the results are not skewed by non-fitting countries. Afterwards, we discuss robustness checks where we test for measurement invariance without item 7 and where we include all countries. 


\subsection{Cross-Country Measurement Invariance}

\subsubsection{Configural Invariance}

First, we test configural invariance on the 2016 wave across the 24 countries with a good fit. The results of this test demonstrate a good fit (RMSEA $=0.060, \mathrm{CFI}=0.986$, $\mathrm{TLI}=0.975$, SRMR $=0.042-\mathrm{M} 1$ in Table 1$)$. We then replicate the configural model for the 2011 and 2007 waves (see M5 and M9 in Table 1). A good fit is achieved for the configural model, both in 2011 in 22 countries (RMSEA $=0.054, \mathrm{CFI}=0.987$, TLI $=0.977$, $\mathrm{SRMR}=0.037)$ and in 2007 in all 27 countries $(\mathrm{RMSEA}=0.030, \mathrm{CFI}=0.997, \mathrm{TLI}=0.993$, SRMR $=0.024$ ). Therefore, we conclude that generalized conflict thinking can be measured in a conceptually comparable way.

\subsubsection{Metric Invariance}

In the second step, we test for metric invariance by constraining the factor loadings to be equal across countries. The results for the metric model on the 2016 wave demonstrate a good fit and are summarized in Fig. 4. Compared to the configural model, there is an increase of 0.005 in RMSEA, a decrease of -0.011 in CFI and -0.005 in TLI and an increase of 0.012 in SRMR (M2 in Table 1). Though deterioration of the CFI is 0.001 above the recommended cut-off value, metric invariance can be reasonably assumed as the value of the TLI is within the boundaries and further analyses support metric invariance. A comparison of the metric model with the configural model for 2011 ( $\triangle \mathrm{RMSEA}=0.004$, $\Delta \mathrm{CFI}=-0.010, \Delta \mathrm{TLI}=-0.004, \Delta \mathrm{SRMR}=0.010)$ and $2007 \quad(\Delta \mathrm{RMSEA}=0.005$, $\Delta \mathrm{CFI}=-0.010, \Delta \mathrm{TLI}=-0.010, \Delta \mathrm{SRMR}=0.014)$ indicates a good fit in both waves (M6 and M10 in Table 1).

\subsubsection{Scalar Invariance}

In the third step, we test for scalar invariance by constraining the factor loadings and intercepts to be equal across countries. The results of the scalar model (M3 in Table 1) demonstrate a significant deterioration in goodness-of-fit statistics, with an increase in RMSEA of 0.058, a decrease in CFI of -0.095 and TLI of -0.077 , and an increase in SRMR of 0.047 . These values all exceed the recommended cut-off values. Scalar invariance is problematic in the 2011 and 2007 waves as well. The full scalar invariant models for $2011(\triangle \mathrm{RMSEA}=0.053, \Delta \mathrm{CFI}=-0.087, \Delta \mathrm{TLI}=-0.071, \Delta \mathrm{SRMR}=0.043)$ and 2007 $(\triangle \mathrm{RMSEA}=0.095, \Delta \mathrm{CFI}=-0.165, \Delta \mathrm{TLI}=-0.144, \Delta \mathrm{SRMR}=0.069)$ indicate a significantly worse fit compared to the metric models (M7 and M11 in Table 1). Therefore, full scalar invariance does not hold.

Subsequently, we seek to ascertain partial scalar invariance. Additional scrutiny of the results shows that the intercepts of item 2: conflict between managers and workers and item 4: conflict between young and old people, vary the least between countries for all three waves. Therefore, we only constrain the intercepts of these items to be invariant and leave the rest of the intercepts to be estimated freely. Allowing the other intercepts to vary across countries results in a model where partial scalar invariance is reached for the 2016 wave (M4 in Table 1). Compared to the metric model, the partial scalar model shows an increase in RMSEA of 0.005 , a decrease in CFI of -0.008 and TLI of -0.005 and an increase in 


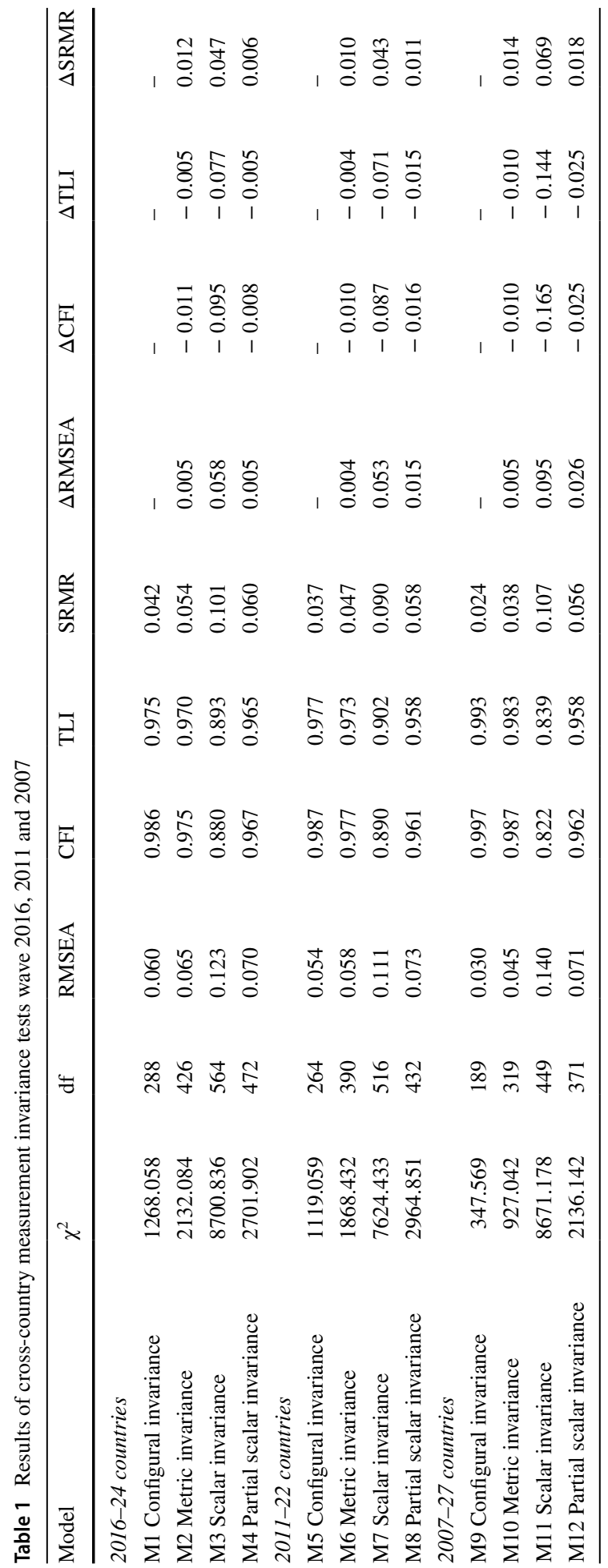




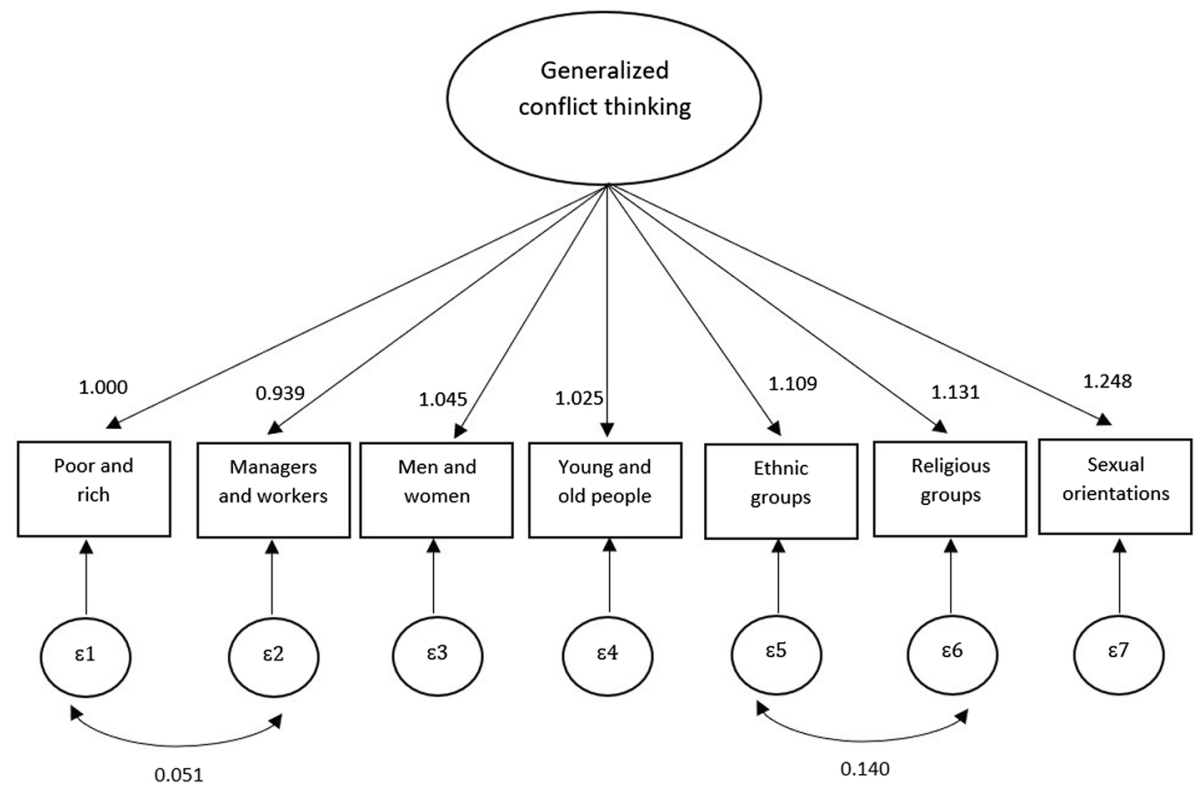

Fig. 4 Metric invariance model 2016 wave. Note: Loadings for the 2011 wave: poor and rich: 1.000 , managers and workers: 0.929 , men and women: 1.160 , young and old: 1.195 , ethnic groups: 1.165 , religious groups: 1.302, sexual orientations 1.321. Covariances: $\varepsilon 1-\varepsilon 2$ : $0.051, \varepsilon 5-\varepsilon 6$ : 0.103 . Loadings for the 2007 wave: poor and rich: 1.000, managers and workers: 0.908, men and women: 1.125, young and old: 1.189, ethnic groups: 0.936, religious groups: 0.931. Covariances: $\varepsilon 1-\varepsilon 2$ : $0.093, \varepsilon 5-\varepsilon 6: 0.117$

SRMR of 0.006. All these values are within the range of the cut-off values. This implies that partial scalar invariance is found in the 2016 wave. However, the partial scalar invariant models for $2011(\triangle \mathrm{RMSEA}=0.015, \Delta \mathrm{CFI}=-0.016, \Delta \mathrm{TLI}=-0.015, \Delta \mathrm{SRMR}=0.011)$ and $2007(\Delta \mathrm{RMSEA}=0.026, \Delta \mathrm{CFI}=-0.025, \Delta \mathrm{TLI}=-0.025, \Delta \mathrm{SRMR}=0.018)$ indicate a significantly worse fit compared to the metric models (M8 and M12 in Table 1).

Since full scalar invariance is not reached for all three waves, it is not possible to compare the means of the latent variable across countries. Nevertheless, for the 2016 wave, partial scalar invariance is sustained among 24 countries. This implies that it is possible to compare the latent means across this sample of countries in 2016. However, since the findings are not robust over multiple waves and full scalar invariance is not met, caution is advised when doing so.

\subsection{Robustness Checks}

Robustness of the results is tested by several alternative model specifications. First, we test the measurement invariance of a model where item 7 is excluded. Removing this item leads to a good fit in all countries, except in Greece for 2016, and does not significantly affect measurement invariance (see online "Appendix"). Moreover, it shows that the theoretical basis underlying the concept of generalized concept thinking is not dependent on the specific items used here. 
Second, we reran the measurement invariance tests across all countries for both our initial model, which includes item 7 and for the model without item 7 . This was done by loosening the restrictions of our conservative method where we excluded countries based on their country-specific model fit. The results remain stable when we include all 27 countries (see online "Appendix").

This implies that the configural and metric invariance hold for all 27 countries across all waves, as does the partial scalar invariance for the 2016 wave.

Third, we checked the correlation between our latent measure and the composite score (constructed by the directly observed items), as composite scores are sometimes more practical in use (Saris \& Gallhofer, 2012). The correlation between the composite score and the latent variable is above 0.95 and highly significant in all countries for every wave (see online "Appendix"). Nevertheless, as generalized conflict thinking remains a latent variable and scalar invariance is not sustained, we advise against using composite scores for theoretical reasons. Fourth, it is important to keep in mind that the cut-off criteria that we applied are strict and much debate regarding these criteria remains. Using alternative and less strict cut-off criteria that are widely used in comparative research (e.g., van de Vijver et al., 2019), ${ }^{5}$ we find configural and metric invariance for all 27 countries in 2016, 2011 and 2007 by using six or seven items. This holds for all countries, except for Slovakia in 2016, and Slovenia and Latvia in 2011, when we include item 7.

\section{Conclusion and Discussion}

Against the background of a series of societal crises and the omnipresence of conflict discourses in the public sphere in many countries, this paper examined the perception of societal conflicts among the wider public across 27 European countries. Moreover, applying MGCFA we assessed the scale properties and cross-cultural measurement invariance of a measure for generalized conflict thinking. Using data from the EQLS we find (1) substantial cross-country and longitudinal trend variation in the salience of perceived societal conflicts and (2) that specific perceptions of conflict are structured by an underlying general orientation, that can be measured by a one-dimensional scale in every country and is metric invariant across a large sample of countries. These findings have proven to be robust. Testing different model specifications in each country independently and across waves, we take into account that CFA approaches strongly depend on observational data and overcome confirmation bias whereby positive evaluation of the measurement model depends upon a single sample (Kline, 2011). Using conservative cut-off values and replicating the analyses across waves, we find that the latent structure of generalized conflict thinking is the same across a large set of countries. However, less robust findings are found for scalar invariance. While scalar invariance is often too strict when working with many groups (Davidov et al., 2014), partial scalar invariance is only sustained for the 2016 wave. Therefore, scholars should be cautious when comparing the means of generalized conflict thinking across countries. In this section, we elaborate on the implications of our findings and outline a research agenda.

\footnotetext{
${ }^{5}$ Configural level CFI or TLI $\leq 0.090$ and RMSEA $\leq 0.080$ or SRMR $\leq 0.060$. Metric level $\mathrm{CFI}<0.010$ or TLI $<0.015$ and RMSEA $<0.015$ or SRMR $\leq 0.030$. Scalar level $\mathrm{CFI}<0.010$ or $\mathrm{TLI}<0.015$ and RMSEA $<0.015$ or SRMR $\leq 0.010$ (OECD, 2018 p. 207).
} 
On a theoretical level, focussing on conflict thinking by assessing the salience of societal conflict aligns with a broader theoretical debate on belief systems (Baldassarri \& Goldberg, 2014; Converse, 1964; Daenekindt et al., 2017; Goldberg, 2011). Thinking in terms of belief systems entails a shift in focus from what people think to how they think and structure their opinions. Indeed, we understand conflict thinking as a logic that connects specific perceptions of conflict and captures people's tendency to perceive society through the lens of conflict. Conflict thinking, as such, is a cognitive perception scheme that directs people's attention and colours their interpretations of events. Distinguishing between preference and salience, the reasoning behind conflict thinking is that people may strongly differ in terms of the specific groups they prefer, but at the same time agree on the level of perceived conflict between two groups. Theoretically, the relationship between salience and preference is expected to be asymmetric: people who have a strong preference for a group (e.g. Muslims) and dislike another (e.g., Christians), are likely to perceive a high level of conflict between both groups but the reverse pattern may not be true. Further research should not only distinguish the salience of perceived societal conflict from preferences in conflicts (i.e. polarization) but also empirically study their interrelations. A specific research question that can follow from this is to what extent perceived societal conflict and polarization are correlated and whether we can indeed identify groups of citizens who perceive high levels of conflict between groups, but do not strongly dislike out-groups. The latter question refers to a more general issue. We have provided robust evidence that generalized conflict thinking can be measured empirically, yet the individual-level characteristics and the attitudinal profile of people who tend towards to conflict thinking remain to be studied. Earlier work showed that for various reasons, conflict thinking attracts people who feel vulnerable (Spruyt et al., 2018). In this sense, conflict thinking functions as a defensive strategy making it easier to cope with feelings of vulnerability by blaming 'the other' for their situation (Hogg, 2000; Mummendey et al., 1999). This mechanism has also been identified in populism and in more generalized prejudice, which originates in people's feelings of vulnerability (Gest, 2016). We theorized that populism and (generalized) prejudice may be part and parcel of a general tendency to perceive society as inherently conflictual. Indeed, a modest attempt to test such mechanisms shows besides some social differences that ethnic prejudice and political trust are significantly correlated with conflict thinking. People who are more ethnically prejudiced and show lower levels of political trust are more inclined to perceive societal conflict in society (see online "Appendix" for a more detailed discussion). However, since our current data does not include any further measures of political attitudes and behaviour it does not allow an in-depth exploration of such mechanisms. A next step is to study whether conflict thinking consistently relates to political attitudes such as populism (Akkerman et al., 2014; Hawkins et al., 2012) and ethnic prejudice (Akrami et al., 2011) and assess whether conflict thinking spills over to specific policy preferences or voting behaviour, and support for populist parties. Moreover, it is plausible that some people are more likely to be inclined to adhere to conflict thinking, such as people who score high on authoritarianism or social dominance orientation (Altemeyer, 2004; Pratto et al., 1994). Further research is needed that studies the possible (moderation) effects of such socio-psychological profiles on conflict thinking. Not only is the generalized level of conflict thinking likely to vary across individuals, different segments of the population might perceive some conflicts to be more salient than others and also adhere to different belief systems that structure their perceptions of conflict. In this context, Daenekindt et al. (2017) uncovered three belief 
systems that structure people's cultural attitudes. While some people adhere to an integrated belief system, where cultural issues are considered to be logically connected, others adhere to a partitioned belief system which does not represent such a coherent view. Further research applying correlation class analysis (CCA) (Boutyline, 2017; Goldberg, 2011) should reveal whether segments of the population structure their perceptions of conflict in different ways. Moreover, as generalized conflict thinking is conceived of as being a logic, it can also be measured using other items than the ones we investigated: as long as they express the amount of conflict people perceive between pairs of groups and cover a broad enough range of groups, conflict thinking can be measured regardless of the specificity of the groups. Further research should develop measures of generalized conflict thinking that include enough items to distinguish different sub-dimensions of conflict thinking. For example, as political space is structured along two dimensions (Kriesi et al., 2008) it is very possible that an economic and cultural sub-dimension of conflict thinking can also be distinguished. Indeed, the high correlations between perceived conflict between poor and rich people and managers and workers, and perceived conflict between different ethnic groups and different religious groups suggest this to be the case. When conflict thinking is understood as a logic, correlational research as we performed here cannot offer a full understanding of the phenomenon. We need research designs that allow to include a dynamic element in the analysis to study the mechanism behind conflict thinking. Population-based experiments could help us to investigate its causal origins as well as its behavioural consequences (Druckman et al., 2011). To study the causal origins of conflict thinking, one could manipulate conflict framing in (political) news coverage or political cues to study whether conflict thinking can be activated or enhanced. Furthermore, one could study how conflict frames affect different segments of the population by differentiating between groups (i.e., higher and less educated people). Such an approach builds upon work by Forgette and Morris (2006) and Ruggiero (2014), who demonstrate that conflict-laden news coverage leads to negative perceptions of political institutions and elites. In addition, it follows and expands on recent work in political communication that uses experimental designs to study the persuasiveness of populist messages and how populist messages affect citizens (Bos et al., 2013; Hameleers et al., 2017). This allows us to hypothesize that conflict thinking functions as a mediating factor (conflict framing stimulates conflict thinking which causes the observed effects) and that the effects of conflict framing will be stronger/weaker among different segments of the population.

Finally, we showed that substantial cross-country variation exists in the amount of perceived conflict between different groups. Nevertheless, it remains unclear how exactly these differences come about. Since we have established that metric invariance is sustained across a large sample of countries, further research should focus on how characteristics of the social context affect individual-level conflict thinking. Variation can be expected to relate to historical factors, such as the cleavage structure in societies (Kriesi et al., 2008; Lipset \& Rokkan, 1967), or the communist legacy in Eastern European countries (Kitschelt, 1995; Rohrschneider \& Whitefield, 2009). Indeed, such a link seems plausible as we find clear regional differences; where people in Eastern European countries perceive more conflict between economic groups of poor and rich people and managers and workers, people in Western European countries perceive more cultural conflict between different ethnic groups and religious groups. Moreover, the salience of conflict thinking is likely to relate to the supply side of politics, such as the presence of strong populist parties, the politicization of certain issues and the level of elite and party polarization (Dalton, 2008). 
Studying the dynamics between these supply-side factors and individual-level conflict thinking are crucial to understanding how conflict thinking comes about.

The preceding arguments identify interesting new opportunities for research that overcome the limitations of this study. They do not, however, invalidate this paper's main contribution: demonstrating that items tapping into perceived societal conflict are interesting social indicators, which show large cross-country and longitudinal trend variation in contemporary Europe. Although each of these indicators has an idiosyncratic aspect to it, we found strong evidence that responses on the specific items are at least partially determined by more generalized conflict thinking that can be measured and used for comparative research. Given the major societal challenges ahead and the abundance of conflict discourse, it seems important to continue to monitor perceived societal conflict and study its causal antecedents and consequences.

\section{Appendix}

This "Appendix" accompanies the article "The salience of perceived societal conflict in Europe: a 27 country study on the development of a measure for generalized conflict thinking' and will be made available through the Open Science Framework after acceptance.

Table 2 presents descriptive statistics of the level of perceived conflict between seven pairs of groups in the four waves for each country.

Table 3 presents the country-specific fit statistics of the confirmatory factor analyses.

Table 4 presents the results of a robustness check where item 7 (Different sexual orientations) is left out of the measurement invariance test.

Table 5 presents the results of the measurement invariance test when all 27 countries are included.

Table 6 presents the bivariate correlations between the summation scale and the factor scores as estimated by the CFA. All correlations turn out to be high, suggesting that the impact of possible deviations from the invariance prerequisite are very small.

Table 7 presents the multi-level models of socio-demographic characteristics, ethnic prejudice and political trust on generalized conflict thinking. 
Table 2 Percentage of people perceiving a lot of tension between each of the seven pairs of groups in each country and per region

\begin{tabular}{|c|c|c|c|c|c|}
\hline & $2003(\%)$ & $2007(\%)$ & $2011(\%)$ & $2016(\%)$ & Total (\%) \\
\hline \multicolumn{6}{|l|}{ 1. Austria } \\
\hline Mean score & 27.30 & 20.70 & 22.90 & 22.80 & 23.40 \\
\hline Poor and rich people & 30.70 & 19.50 & 24.10 & 25.90 & 25.10 \\
\hline Managers and workers & 29.10 & 17.60 & 25.00 & 21.10 & 23.10 \\
\hline Men and women & 13.60 & 11.10 & 11.80 & 8.30 & 11.00 \\
\hline Young and old people & 22.20 & 15.20 & 13.90 & 8.40 & 14.60 \\
\hline Different ethnic groups & 41.20 & 41.00 & 40.20 & 50.80 & 43.60 \\
\hline Different religious groups & & 41.40 & 31.00 & 50.50 & 41.40 \\
\hline Different sexual orientations & & & 13.80 & 11.60 & 12.60 \\
\hline \multicolumn{6}{|l|}{ 2. Belgium } \\
\hline Mean score & 33.60 & 24.10 & 27.10 & 28.60 & 28.30 \\
\hline Poor and rich people & 36.60 & 24.40 & 32.40 & 34.10 & 31.90 \\
\hline Managers and workers & 34.60 & 22.60 & 30.00 & 31.20 & 29.60 \\
\hline Men and women & 16.80 & 11.40 & 12.00 & 13.00 & 13.30 \\
\hline Young and old people & 21.70 & 18.20 & 12.80 & 12.00 & 16.10 \\
\hline Different ethnic groups & 59.80 & 44.70 & 48.90 & 52.90 & 51.50 \\
\hline Different religious groups & & 31.70 & 38.10 & 52.70 & 40.90 \\
\hline Different sexual orientations & & & 13.70 & 14.70 & 14.20 \\
\hline \multicolumn{6}{|l|}{ 3. Bulgaria } \\
\hline Mean score & 26.20 & 14.20 & 14.30 & 13.50 & 17.00 \\
\hline Poor and rich people & 54.30 & 28.10 & 24.00 & 20.10 & 31.60 \\
\hline Managers and workers & 37.20 & 16.60 & 15.20 & 15.70 & 20.90 \\
\hline Men and women & 9.50 & 3.70 & 5.60 & 2.80 & 5.30 \\
\hline Young and old people & 17.50 & 12.00 & 9.40 & 6.40 & 11.30 \\
\hline Different ethnic groups & 11.90 & 12.80 & 18.60 & 23.50 & 16.90 \\
\hline Different religious groups & & 8.50 & 12.50 & 17.80 & 13.30 \\
\hline Different sexual orientations & & & 12.10 & 14.80 & 13.50 \\
\hline \multicolumn{6}{|l|}{ 4. Cyprus } \\
\hline Mean score & 13.90 & 11.60 & 36.10 & 14.90 & 19.80 \\
\hline Poor and rich people & 17.80 & 11.00 & 41.00 & 20.40 & 23.30 \\
\hline Managers and workers & 16.70 & 10.50 & 38.70 & 20.30 & 22.20 \\
\hline Men and women & 10.90 & 8.20 & 31.40 & 8.70 & 15.30 \\
\hline Young and old people & 9.10 & 7.20 & 25.10 & 5.80 & 12.20 \\
\hline Different ethnic groups & 16.70 & 22.00 & 45.10 & 19.90 & 27.10 \\
\hline Different religious groups & & 13.90 & 38.60 & 16.90 & 23.30 \\
\hline Different sexual orientations & & & 38.30 & 17.50 & 28.10 \\
\hline \multicolumn{6}{|l|}{ 5. Czech Republic } \\
\hline Mean score & 31.10 & 30.40 & 37.20 & 26.70 & 31.30 \\
\hline Poor and rich people & 43.80 & 39.60 & 48.40 & 31.80 & 40.70 \\
\hline Managers and workers & 34.90 & 33.90 & 39.50 & 28.10 & 34.00 \\
\hline Men and women & 6.30 & 6.80 & 8.90 & 5.40 & 6.80 \\
\hline Young and old people & 15.70 & 20.30 & 20.40 & 15.80 & 18.20 \\
\hline Different ethnic groups & 55.20 & 51.70 & 68.60 & 52.20 & 56.70 \\
\hline Different religious groups & & 24.90 & 25.90 & 33.20 & 27.90 \\
\hline
\end{tabular}


Table 2 (continued)

\begin{tabular}{|c|c|c|c|c|c|}
\hline & $2003(\%)$ & $2007(\%)$ & $2011(\%)$ & $2016(\%)$ & Total $(\%)$ \\
\hline Different sexual orientations & & & 14.70 & 12.50 & 13.50 \\
\hline \multicolumn{6}{|l|}{ 6. Germany } \\
\hline Mean score & 25.30 & 27.10 & 19.60 & 23.60 & 23.20 \\
\hline Poor and rich people & 36.00 & 36.30 & 32.30 & 30.90 & 33.50 \\
\hline Managers and workers & 34.50 & 41.60 & 23.10 & 26.60 & 30.20 \\
\hline Men and women & 6.70 & 9.90 & 6.20 & 6.90 & 7.40 \\
\hline Young and old people & 13.00 & 15.60 & 9.00 & 8.70 & 11.20 \\
\hline Different ethnic groups & 37.50 & 33.00 & 27.80 & 45.20 & 34.20 \\
\hline Different religious groups & & 31.60 & 27.10 & 46.40 & 33.20 \\
\hline Different sexual orientations & & & 7.80 & 10.70 & 8.80 \\
\hline \multicolumn{6}{|l|}{ 7. Denmark } \\
\hline Mean score & 11.60 & 10.50 & 7.60 & 9.70 & 9.80 \\
\hline Poor and rich people & 4.10 & 4.10 & 4.40 & 6.00 & 4.70 \\
\hline Managers and workers & 5.10 & 3.60 & 4.10 & 4.30 & 4.30 \\
\hline Men and women & 6.10 & 4.80 & 3.00 & 2.20 & 4.00 \\
\hline Young and old people & 3.10 & 3.80 & 1.90 & 2.20 & 2.70 \\
\hline Different ethnic groups & 38.70 & 36.20 & 24.70 & 34.10 & 33.40 \\
\hline Different religious groups & & 32.90 & 20.80 & 29.60 & 27.80 \\
\hline Different sexual orientations & & & 3.70 & 10.70 & 7.20 \\
\hline \multicolumn{6}{|l|}{ 8. Estonia } \\
\hline Mean score & 21.90 & 18.80 & 20.30 & 20.10 & 20.10 \\
\hline Poor and rich people & 51.60 & 31.80 & 40.80 & 31.20 & 37.40 \\
\hline Managers and workers & 20.10 & 19.80 & 23.40 & 19.50 & 20.70 \\
\hline Men and women & 5.60 & 8.20 & 9.10 & 9.40 & 8.40 \\
\hline Young and old people & 17.50 & 17.00 & 12.50 & 14.50 & 15.10 \\
\hline Different ethnic groups & 11.60 & 17.40 & 15.60 & 26.10 & 18.40 \\
\hline Different religious groups & & 6.70 & 8.70 & 14.00 & 9.90 \\
\hline Different sexual orientations & & & 18.20 & 23.90 & 21.10 \\
\hline \multicolumn{6}{|l|}{ 9. Greece } \\
\hline Mean score & 46.60 & 30.80 & 38.90 & 21.30 & 33.90 \\
\hline Poor and rich people & 58.40 & 35.40 & 51.60 & 25.20 & 42.00 \\
\hline Managers and workers & 61.50 & 46.40 & 59.50 & 30.60 & 48.90 \\
\hline Men and women & 28.70 & 17.80 & 18.30 & 8.80 & 18.10 \\
\hline Young and old people & 28.30 & 20.20 & 19.80 & 10.30 & 19.30 \\
\hline Different ethnic groups & 58.50 & 34.80 & 46.60 & 32.30 & 42.50 \\
\hline Different religious groups & & 21.90 & 30.40 & 30.20 & 27.60 \\
\hline Different sexual orientations & & & 26.70 & 14.70 & 19.90 \\
\hline \multicolumn{6}{|l|}{ 10. Spain } \\
\hline Mean score & 28.40 & 26.20 & 22.30 & 19.60 & 23.90 \\
\hline Poor and rich people & 31.30 & 23.90 & 26.70 & 25.10 & 26.70 \\
\hline Managers and workers & 35.40 & 32.70 & 31.10 & 26.70 & 31.40 \\
\hline Men and women & 20.40 & 21.30 & 11.80 & 9.80 & 15.40 \\
\hline Young and old people & 15.10 & 19.60 & 12.60 & 9.40 & 14.00 \\
\hline Different ethnic groups & 41.30 & 34.70 & 30.40 & 27.70 & 33.10 \\
\hline
\end{tabular}


Table 2 (continued)

\begin{tabular}{|c|c|c|c|c|c|}
\hline & $2003(\%)$ & $2007(\%)$ & $2011(\%)$ & $2016(\%)$ & Total (\%) \\
\hline Different religious groups & & 22.40 & 21.30 & 25.90 & 22.90 \\
\hline Different sexual orientations & & & 13.70 & 16.30 & 14.70 \\
\hline \multicolumn{6}{|l|}{ 11. Finland } \\
\hline Mean score & 18.40 & 14.70 & 15.20 & 13.60 & 15.40 \\
\hline Poor and rich people & 21.90 & 14.20 & 17.40 & 17.60 & 17.80 \\
\hline Managers and workers & 17.10 & 14.40 & 14.60 & 11.20 & 14.30 \\
\hline Men and women & 8.40 & 5.30 & 4.00 & 3.00 & 5.10 \\
\hline Young and old people & 8.80 & 7.00 & 5.60 & 3.60 & 6.20 \\
\hline Different ethnic groups & 36.50 & 33.10 & 35.20 & 33.30 & 34.50 \\
\hline Different religious groups & & 16.80 & 20.30 & 20.00 & 19.00 \\
\hline Different sexual orientations & & & 20.10 & 15.80 & 17.80 \\
\hline \multicolumn{6}{|l|}{ 12. France } \\
\hline Mean score & 38.80 & 34.00 & 36.40 & 31.30 & 35.20 \\
\hline Poor and rich people & 46.90 & 43.70 & 55.70 & 39.50 & 48.00 \\
\hline Managers and workers & 49.90 & 44.80 & 49.30 & 39.10 & 46.20 \\
\hline Men and women & 11.80 & 11.90 & 12.10 & 13.10 & 12.20 \\
\hline Young and old people & 23.30 & 16.70 & 15.30 & 12.30 & 16.40 \\
\hline Different ethnic groups & 62.90 & 54.10 & 50.00 & 53.10 & 53.90 \\
\hline Different religious groups & & 40.70 & 38.00 & 54.50 & 42.90 \\
\hline Different sexual orientations & & & 19.90 & 27.20 & 22.40 \\
\hline \multicolumn{6}{|l|}{ 13. Hungary } \\
\hline Mean score & 39.20 & 47.10 & 46.50 & 38.70 & 42.90 \\
\hline Poor and rich people & 62.30 & 70.10 & 71.20 & 59.10 & 65.60 \\
\hline Managers and workers & 47.60 & 62.80 & 60.40 & 49.90 & 55.20 \\
\hline Men and women & 11.80 & 21.50 & 16.30 & 13.60 & 15.80 \\
\hline Young and old people & 19.60 & 32.70 & 26.90 & 20.60 & 24.90 \\
\hline Different ethnic groups & 55.00 & 49.20 & 59.10 & 51.20 & 53.60 \\
\hline Different religious groups & & 21.90 & 23.60 & 28.60 & 24.80 \\
\hline Different sexual orientations & & & 36.40 & 29.40 & 32.90 \\
\hline \multicolumn{6}{|l|}{ 14. Ireland } \\
\hline Mean score & 25.70 & 17.40 & 17.30 & 13.50 & 18.40 \\
\hline Poor and rich people & 28.50 & 17.20 & 27.10 & 18.60 & 22.90 \\
\hline Managers and workers & 26.90 & 17.70 & 21.90 & 18.60 & 21.30 \\
\hline Men and women & 11.90 & 8.00 & 5.80 & 6.60 & 8.00 \\
\hline Young and old people & 14.60 & 10.70 & 5.10 & 4.10 & 8.50 \\
\hline Different ethnic groups & 45.80 & 33.00 & 27.50 & 20.20 & 31.50 \\
\hline Different religious groups & & 20.70 & 15.40 & 16.70 & 17.50 \\
\hline Different sexual orientations & & & 14.00 & 13.10 & 13.50 \\
\hline \multicolumn{6}{|l|}{ 15. Italy } \\
\hline Mean score & 21.80 & 30.10 & 25.40 & 25.00 & 25.80 \\
\hline Poor and rich people & 21.50 & 27.40 & 31.80 & 23.80 & 26.90 \\
\hline Managers and workers & 30.50 & 30.70 & 31.70 & 22.00 & 28.40 \\
\hline Men and women & 7.70 & 18.00 & 14.40 & 14.70 & 14.30 \\
\hline Young and old people & 8.20 & 19.30 & 11.80 & 9.40 & 12.20 \\
\hline
\end{tabular}


Table 2 (continued)

\begin{tabular}{|c|c|c|c|c|c|}
\hline & $2003(\%)$ & $2007(\%)$ & $2011(\%)$ & $2016(\%)$ & Total $(\%)$ \\
\hline Different ethnic groups & 40.80 & 55.70 & 38.30 & 54.60 & 47.40 \\
\hline Different religious groups & & 47.50 & 28.20 & 47.10 & 39.90 \\
\hline Different sexual orientations & & & 24.10 & 28.30 & 26.10 \\
\hline \multicolumn{6}{|l|}{ 16. Lithuania } \\
\hline Mean score & 32.00 & 26.10 & 27.00 & 25.50 & 27.60 \\
\hline Poor and rich people & 62.80 & 46.20 & 61.60 & 51.80 & 55.80 \\
\hline Managers and workers & 54.70 & 34.80 & 36.60 & 35.80 & 40.40 \\
\hline Men and women & 8.90 & 12.20 & 6.30 & 7.20 & 8.50 \\
\hline Young and old people & 19.40 & 21.30 & 14.40 & 15.60 & 17.50 \\
\hline Different ethnic groups & 9.30 & 15.80 & 15.00 & 17.10 & 14.40 \\
\hline Different religious groups & & 13.10 & 10.40 & 11.10 & 11.40 \\
\hline Different sexual orientations & & & 35.70 & 38.30 & 36.90 \\
\hline \multicolumn{6}{|l|}{ 17. Luxembourg } \\
\hline Mean score & 20.60 & 30.70 & 24.10 & 21.20 & 24.50 \\
\hline Poor and rich people & 21.20 & 31.90 & 30.80 & 28.40 & 28.90 \\
\hline Managers and workers & 22.40 & 36.20 & 32.90 & 27.60 & 30.60 \\
\hline Men and women & 18.70 & 25.10 & 15.60 & 10.10 & 17.10 \\
\hline Young and old people & 15.70 & 26.00 & 12.40 & 10.60 & 16.20 \\
\hline Different ethnic groups & 25.80 & 34.60 & 29.00 & 30.30 & 30.40 \\
\hline Different religious groups & & 22.40 & 20.40 & 28.40 & 23.80 \\
\hline Different sexual orientations & & & 10.50 & 12.90 & 11.70 \\
\hline \multicolumn{6}{|l|}{ 18. Latvia } \\
\hline Mean score & 23.30 & 17.20 & 18.90 & 16.50 & 19.00 \\
\hline Poor and rich people & 45.10 & 33.90 & 38.10 & 35.60 & 38.10 \\
\hline Managers and workers & 27.10 & 14.20 & 23.20 & 15.60 & 19.90 \\
\hline Men and women & 4.00 & 5.20 & 3.40 & 3.20 & 4.00 \\
\hline Young and old people & 19.70 & 17.40 & 12.80 & 11.30 & 15.30 \\
\hline Different ethnic groups & 19.40 & 14.30 & 16.30 & 16.60 & 16.70 \\
\hline Different religious groups & & 5.90 & 6.80 & 8.30 & 7.00 \\
\hline Different sexual orientations & & & 28.20 & 27.00 & 27.60 \\
\hline \multicolumn{6}{|l|}{ 19. Malta } \\
\hline Mean score & 29.10 & 18.60 & 22.70 & 20.90 & 22.20 \\
\hline Poor and rich people & 26.10 & 13.80 & 28.30 & 16.80 & 20.80 \\
\hline Managers and workers & 33.00 & 19.50 & 24.40 & 25.00 & 24.70 \\
\hline Men and women & 19.70 & 9.90 & 14.30 & 8.00 & 12.20 \\
\hline Young and old people & 18.20 & 8.90 & 11.70 & 7.00 & 10.70 \\
\hline Different ethnic groups & 49.50 & 42.10 & 35.20 & 48.90 & 43.30 \\
\hline Different religious groups & & 16.00 & 19.60 & 26.80 & 20.90 \\
\hline Different sexual orientations & & & 22.10 & 18.10 & 20.00 \\
\hline \multicolumn{6}{|l|}{ 20. Netherlands } \\
\hline Mean score & 27.60 & 21.70 & 21.10 & 20.20 & 22.70 \\
\hline Poor and rich people & 24.60 & 12.10 & 19.00 & 15.90 & 17.90 \\
\hline Managers and workers & 23.80 & 20.20 & 22.20 & 17.80 & 21.00 \\
\hline Men and women & 9.30 & 6.70 & 6.80 & 4.80 & 6.90 \\
\hline
\end{tabular}


Table 2 (continued)

\begin{tabular}{|c|c|c|c|c|c|}
\hline & $2003(\%)$ & $2007(\%)$ & $2011(\%)$ & $2016(\%)$ & Total (\%) \\
\hline Young and old people & 18.60 & 12.90 & 10.80 & 7.70 & 12.50 \\
\hline Different ethnic groups & 61.70 & 57.00 & 47.20 & 53.70 & 54.90 \\
\hline Different religious groups & & 38.20 & 34.10 & 48.10 & 40.10 \\
\hline Different sexual orientations & & & 14.80 & 21.30 & 18.00 \\
\hline \multicolumn{6}{|l|}{ 21. Poland } \\
\hline Mean score & 30.70 & 22.60 & 22.60 & 20.10 & 23.50 \\
\hline Poor and rich people & 52.10 & 32.70 & 34.30 & 28.70 & 35.90 \\
\hline Managers and workers & 52.70 & 31.20 & 31.50 & 25.50 & 34.00 \\
\hline Men and women & 8.50 & 9.70 & 8.80 & 9.00 & 9.00 \\
\hline Young and old people & 17.30 & 19.10 & 15.60 & 13.20 & 16.40 \\
\hline Different ethnic groups & 23.00 & 18.40 & 22.90 & 24.40 & 22.10 \\
\hline Different religious groups & & 16.20 & 21.90 & 22.40 & 20.30 \\
\hline Different sexual orientations & & & 31.80 & 26.90 & 30.20 \\
\hline \multicolumn{6}{|l|}{ 22. Portugal } \\
\hline Mean score & 20.70 & 19.00 & 15.20 & 11.50 & 16.50 \\
\hline Poor and rich people & 23.60 & 23.60 & 20.00 & 9.20 & 18.90 \\
\hline Managers and workers & 23.50 & 26.50 & 23.40 & 16.90 & 22.40 \\
\hline Men and women & 10.20 & 10.60 & 6.00 & 6.20 & 8.20 \\
\hline Young and old people & 10.70 & 12.40 & 6.90 & 5.30 & 8.70 \\
\hline Different ethnic groups & 35.50 & 23.60 & 20.30 & 19.80 & 24.70 \\
\hline Different religious groups & & 14.00 & 9.50 & 10.30 & 11.20 \\
\hline Different sexual orientations & & & 13.10 & 13.70 & 13.40 \\
\hline \multicolumn{6}{|l|}{ 23. Romania } \\
\hline Mean score & 36.10 & 28.50 & 31.90 & 30.20 & 31.70 \\
\hline Poor and rich people & 52.50 & 36.00 & 48.20 & 40.90 & 45.00 \\
\hline Managers and workers & 48.60 & 33.00 & 43.30 & 38.70 & 41.30 \\
\hline Men and women & 17.90 & 16.50 & 14.40 & 18.80 & 16.60 \\
\hline Young and old people & 29.50 & 28.20 & 22.60 & 26.80 & 26.30 \\
\hline Different ethnic groups & 31.80 & 30.00 & 30.90 & 26.30 & 29.90 \\
\hline Different religious groups & & 20.50 & 17.60 & 21.60 & 19.60 \\
\hline Different sexual orientations & & & 25.60 & 37.80 & 31.00 \\
\hline \multicolumn{6}{|l|}{ 24. Sweden } \\
\hline Mean score & 21.40 & 14.20 & 18.10 & 18.50 & 18.00 \\
\hline Poor and rich people & 23.70 & 11.30 & 21.30 & 19.80 & 19.00 \\
\hline Managers and workers & 16.30 & 7.30 & 14.90 & 9.90 & 12.10 \\
\hline Men and women & 10.80 & 6.30 & 8.90 & 10.20 & 9.10 \\
\hline Young and old people & 10.00 & 8.50 & 8.40 & 7.50 & 8.60 \\
\hline Different ethnic groups & 45.50 & 37.80 & 36.50 & 44.30 & 41.00 \\
\hline Different religious groups & & 32.00 & 31.00 & 35.70 & 32.90 \\
\hline Different sexual orientations & & & 13.20 & 13.10 & 13.10 \\
\hline \multicolumn{6}{|l|}{ 25. Slovenia } \\
\hline Mean score & 33.30 & 29.50 & 30.00 & 27.00 & 29.60 \\
\hline Poor and rich people & 43.00 & 37.40 & 41.60 & 34.10 & 38.60 \\
\hline Managers and workers & 48.40 & 47.20 & 56.10 & 43.60 & 48.90 \\
\hline
\end{tabular}


Table 2 (continued)

\begin{tabular}{|c|c|c|c|c|c|}
\hline & $2003(\%)$ & $2007(\%)$ & $2011(\%)$ & $2016(\%)$ & Total $(\%)$ \\
\hline Men and women & 10.50 & 11.80 & 8.10 & 10.30 & 10.10 \\
\hline Young and old people & 21.30 & 21.50 & 12.80 & 16.20 & 17.60 \\
\hline Different ethnic groups & 43.10 & 29.60 & 31.50 & 30.40 & 32.60 \\
\hline Different religious groups & & 19.80 & 29.80 & 26.40 & 25.40 \\
\hline Different sexual orientations & & & 32.60 & 29.70 & 31.20 \\
\hline \multicolumn{6}{|l|}{ 26. Slovakia } \\
\hline Mean score & 30.30 & 19.60 & 19.70 & 16.90 & 21.70 \\
\hline Poor and rich people & 50.00 & 31.00 & 30.50 & 24.40 & 34.10 \\
\hline Managers and workers & 41.40 & 27.40 & 27.50 & 24.30 & 30.10 \\
\hline Men and women & 5.00 & 6.70 & 4.70 & 3.90 & 5.10 \\
\hline Young and old people & 13.70 & 11.30 & 7.80 & 7.80 & 10.20 \\
\hline Different ethnic groups & 41.50 & 22.60 & 29.30 & 24.60 & 29.40 \\
\hline Different religious groups & & 9.60 & 9.50 & 16.20 & 11.70 \\
\hline Different sexual orientations & & & 11.80 & 16.80 & 14.40 \\
\hline \multicolumn{6}{|l|}{ 27. United Kingdom } \\
\hline Mean score & 26.20 & 22.10 & 24.10 & 22.10 & 23.50 \\
\hline Poor and rich people & 23.00 & 17.50 & 31.70 & 28.00 & 25.90 \\
\hline Managers and workers & 26.00 & 19.60 & 23.10 & 21.30 & 22.30 \\
\hline Men and women & 17.50 & 9.80 & 9.80 & 8.30 & 10.80 \\
\hline Young and old people & 18.00 & 21.10 & 15.40 & 11.30 & 16.40 \\
\hline Different ethnic groups & 46.60 & 42.70 & 40.30 & 41.60 & 42.20 \\
\hline Different religious groups & & 33.20 & 32.80 & 38.10 & 34.30 \\
\hline Different sexual orientations & & & 13.30 & 12.70 & 13.10 \\
\hline \multicolumn{6}{|l|}{ Europe } \\
\hline Mean score & 27.80 & 23.70 & 24.70 & 21.50 & 24.43 \\
\hline Poor and rich people & 37.20 & 28.50 & 35.20 & 27.50 & 32.10 \\
\hline Managers and workers & 33.70 & 28.00 & 31.00 & 24.70 & 29.35 \\
\hline Men and women & 11.60 & 11.10 & 10.30 & 8.60 & 10.40 \\
\hline Young and old people & 16.70 & 16.60 & 13.20 & 10.40 & 14.23 \\
\hline Different ethnic groups & 40.00 & 35.10 & 34.60 & 36.70 & 36.60 \\
\hline Different religious groups & & 24.70 & 24.50 & 30.50 & 26.57 \\
\hline Different sexual orientations & & & 19.20 & 19.40 & 19.30 \\
\hline \multicolumn{6}{|l|}{ Western Europe } \\
\hline Mean score & 25.30 & 22.50 & 22.40 & 20.80 & 22.75 \\
\hline Poor and rich people & 27.40 & 23.00 & 30.30 & 24.70 & 26.35 \\
\hline Managers and workers & 26.30 & 24.50 & 25.70 & 21.30 & 24.45 \\
\hline Men and women & 11.70 & 10.00 & 8.70 & 7.90 & 9.58 \\
\hline Young and old people & 15.40 & 14.60 & 10.70 & 8.20 & 12.23 \\
\hline Different ethnic groups & 46.50 & 40.70 & 37.10 & 42.30 & 41.65 \\
\hline Different religious groups & & 31.70 & 29.10 & 39.10 & 33.30 \\
\hline Different sexual orientations & & & 13.10 & 14.80 & 13.95 \\
\hline \multicolumn{6}{|l|}{ Eastern Europe } \\
\hline Mean score & 30.50 & 24.90 & 26.40 & 23.20 & 26.25 \\
\hline Poor and rich people & 52.80 & 38.60 & 43.50 & 36.10 & 42.75 \\
\hline
\end{tabular}


Table 2 (continued)

\begin{tabular}{lrrrrr}
\hline & $2003(\%)$ & $2007(\%)$ & $2011(\%)$ & $2016(\%)$ & Total (\%) \\
\hline Managers and workers & 41.70 & 30.70 & 33.90 & 28.30 & 33.65 \\
Men and women & 8.80 & 9.90 & 8.90 & 8.20 & 8.95 \\
Young and old people & 18.90 & 19.80 & 16.10 & 14.70 & 17.38 \\
Different ethnic groups & 30.30 & 26.50 & 30.20 & 29.50 & 29.13 \\
Different religious groups & & 14.70 & 16.30 & 19.50 & 16.83 \\
Different sexual orientations & & & 25.20 & 25.30 & 25.25 \\
South Europe & & & & & \\
Mean score & 28.20 & 24.30 & 26.70 & 20.60 & 24.95 \\
Poor and rich people & 32.20 & 25.00 & 33.70 & 22.30 & 28.30 \\
Managers and workers & 36.30 & 30.90 & 36.80 & 25.90 & 32.48 \\
Men and women & 15.80 & 14.30 & 14.60 & 10.10 & 13.70 \\
Young and old people & 15.80 & 15.90 & 13.90 & 19.10 & 16.18 \\
Different ethnic groups & 41.70 & 36.20 & 35.50 & 36.00 & 37.35 \\
Different religious groups & & 24.30 & 25.60 & 28.90 & 26.27 \\
Different sexual orientations & & & 23.70 & 20.90 & 22.30 \\
\hline
\end{tabular}




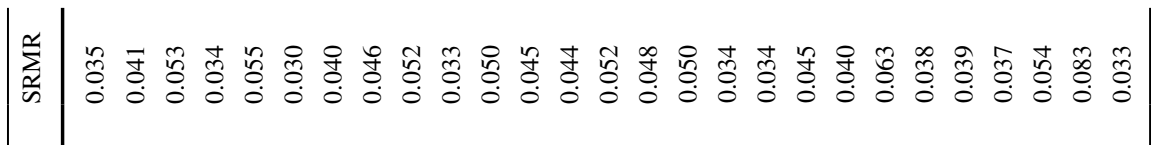

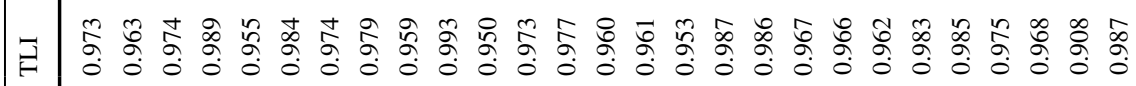

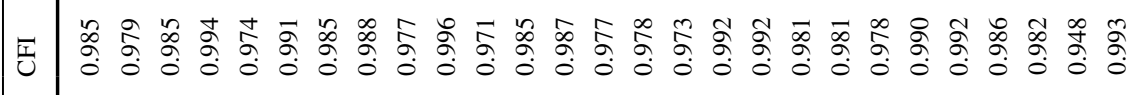

$$
\begin{aligned}
& \text { 通 } \\
& \text { 党 }
\end{aligned}
$$

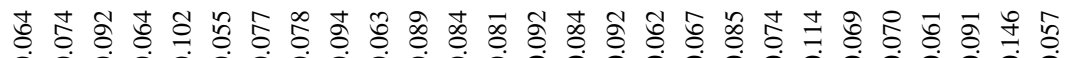

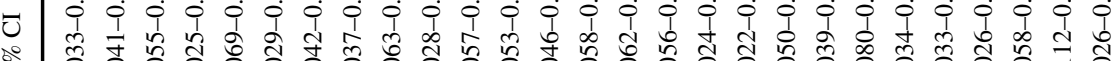

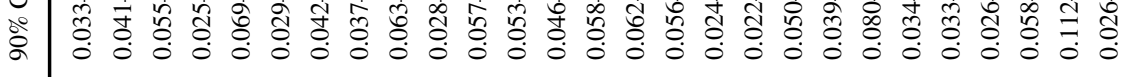

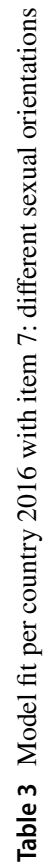

$$
\begin{aligned}
& \text { 畓 }
\end{aligned}
$$

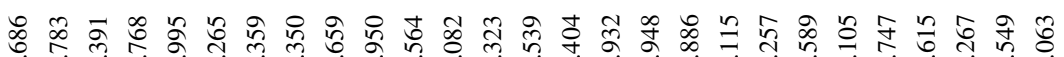

$$
\begin{aligned}
& \text { บี }
\end{aligned}
$$

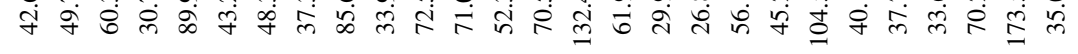

$$
\begin{aligned}
& \text {. }
\end{aligned}
$$

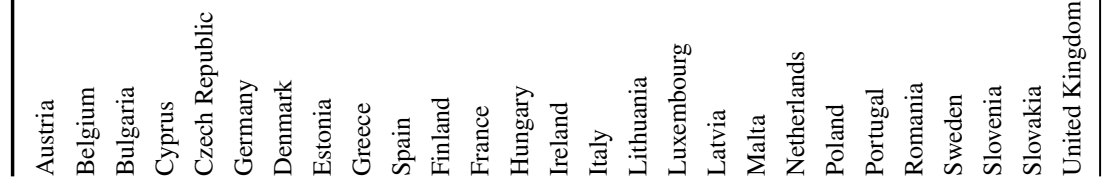




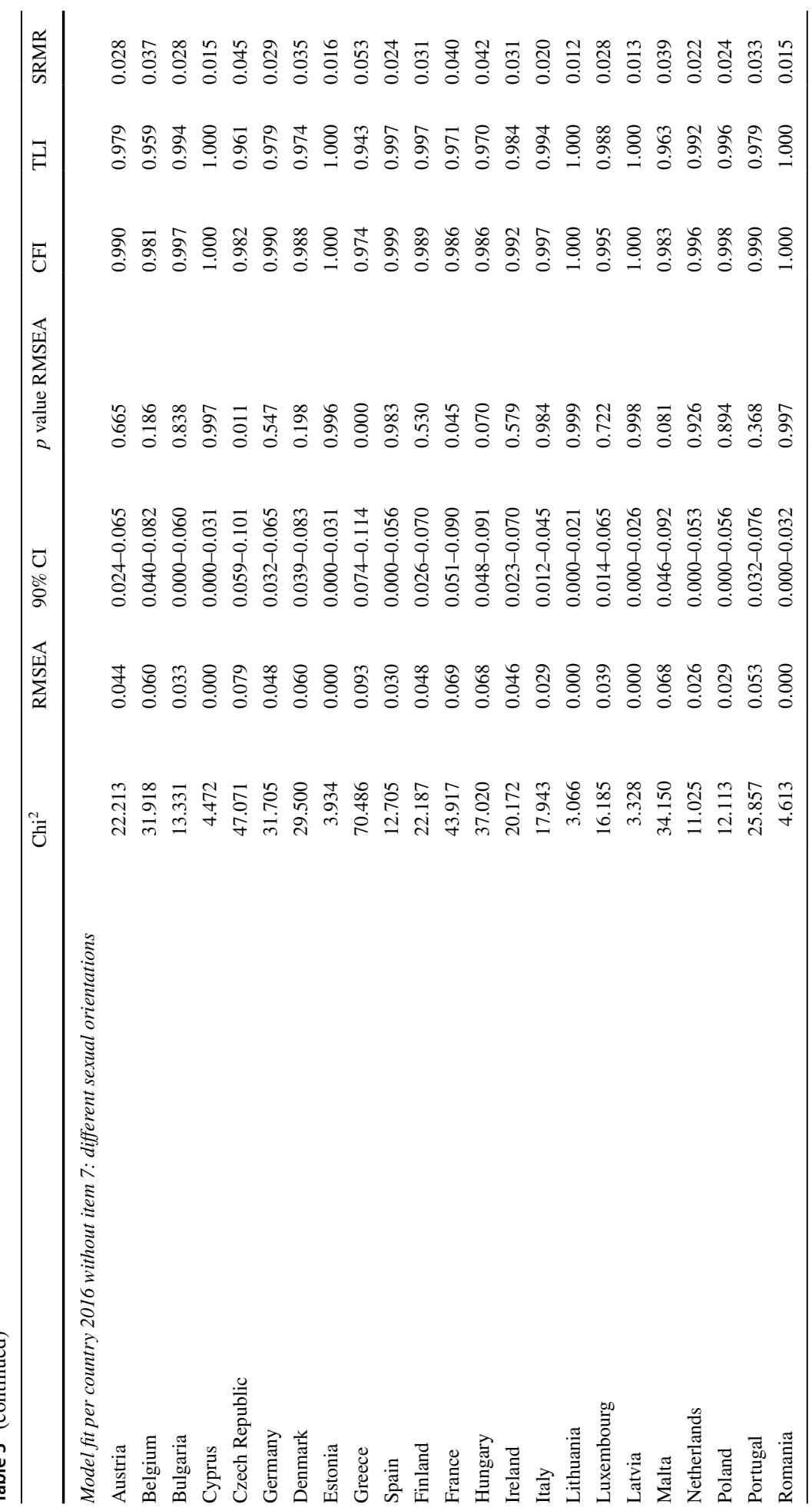




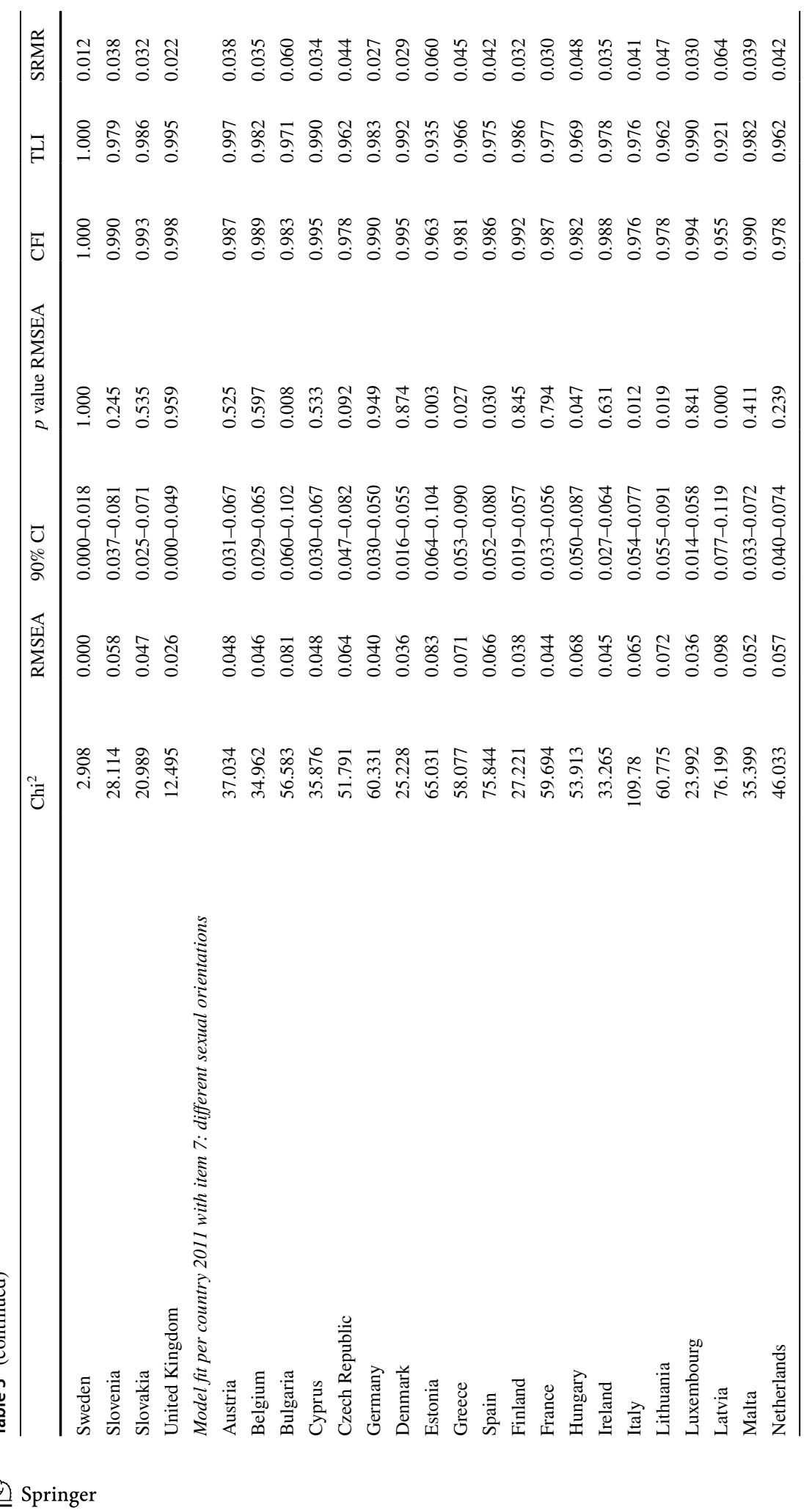




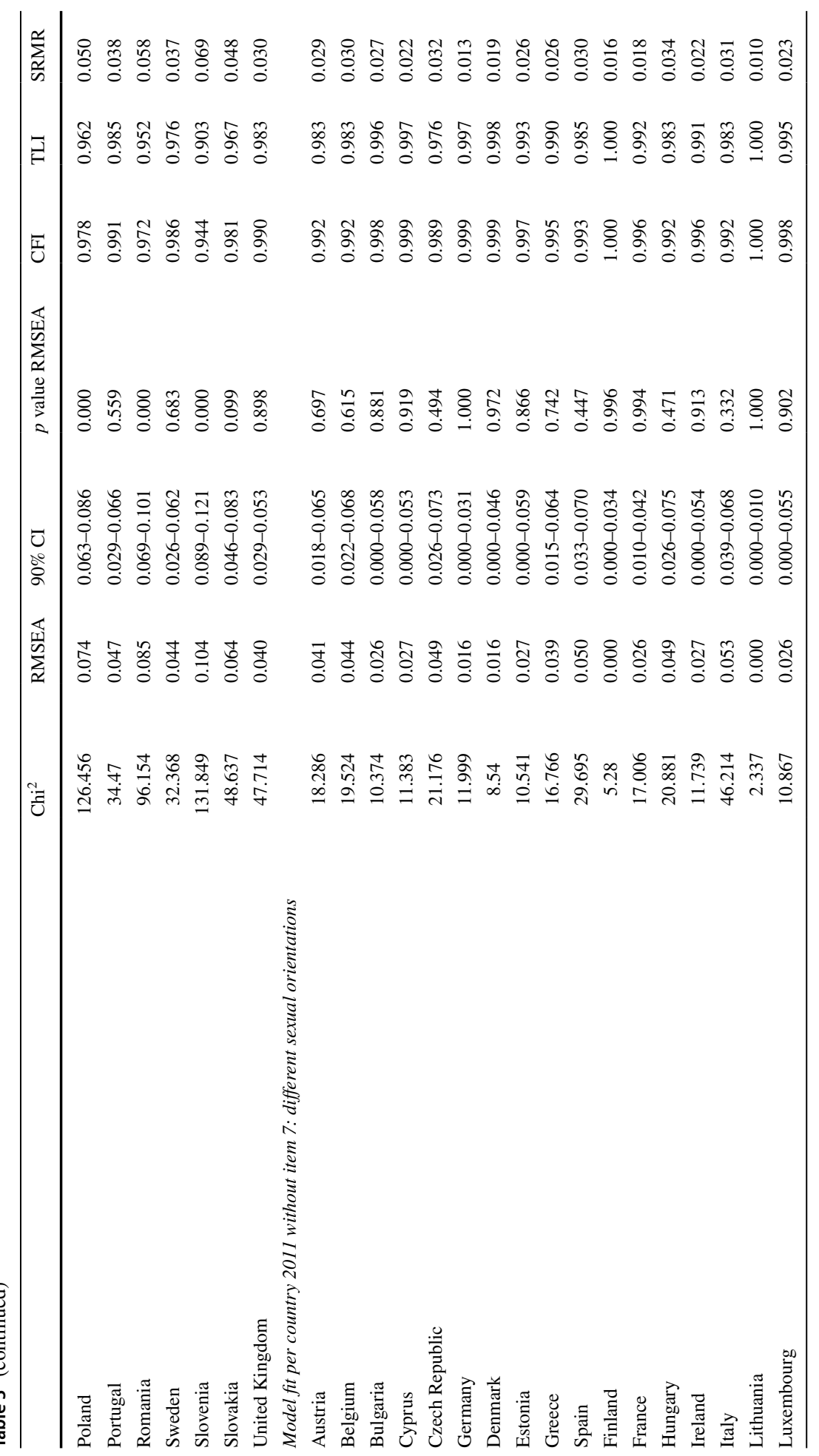




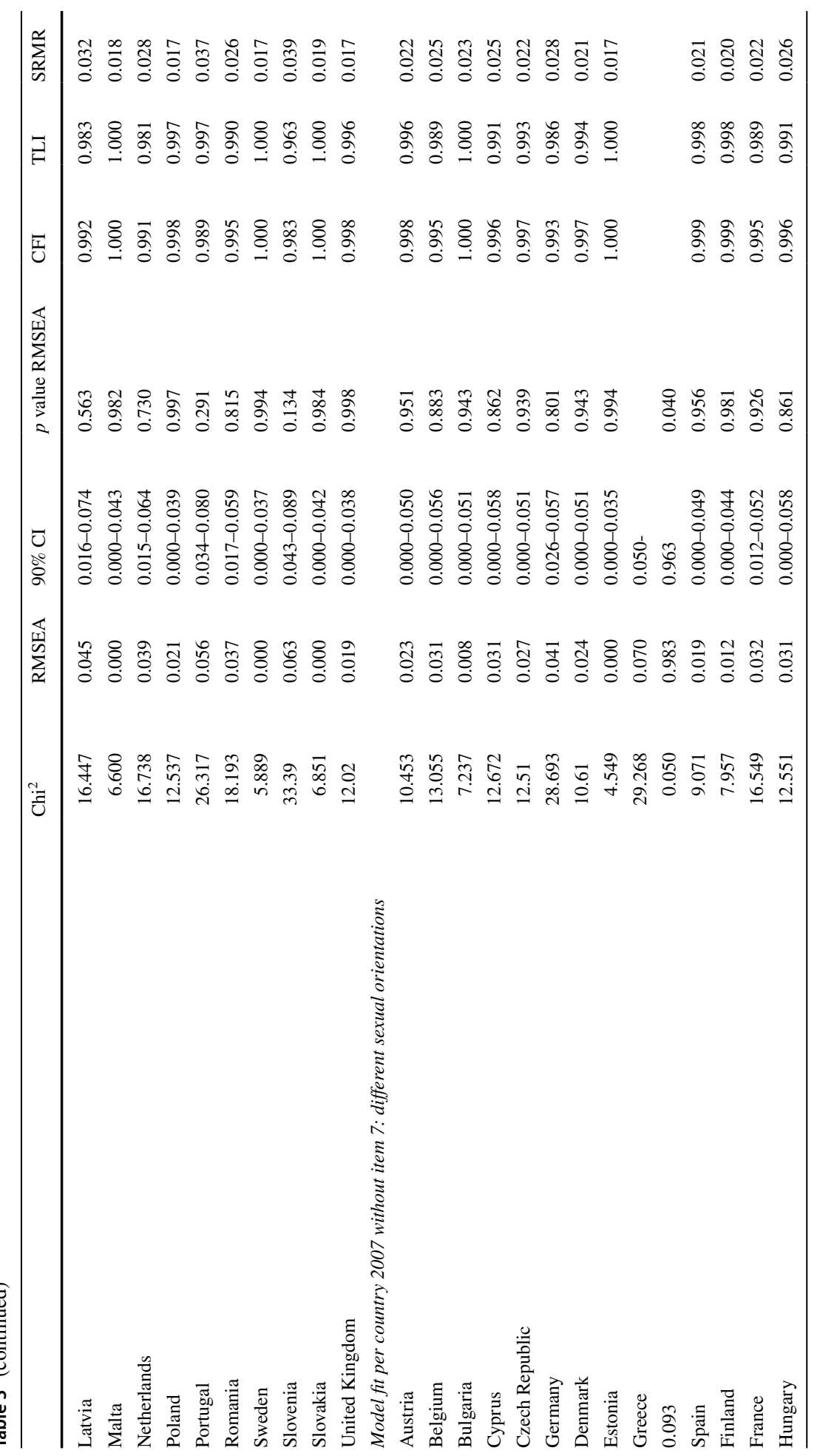




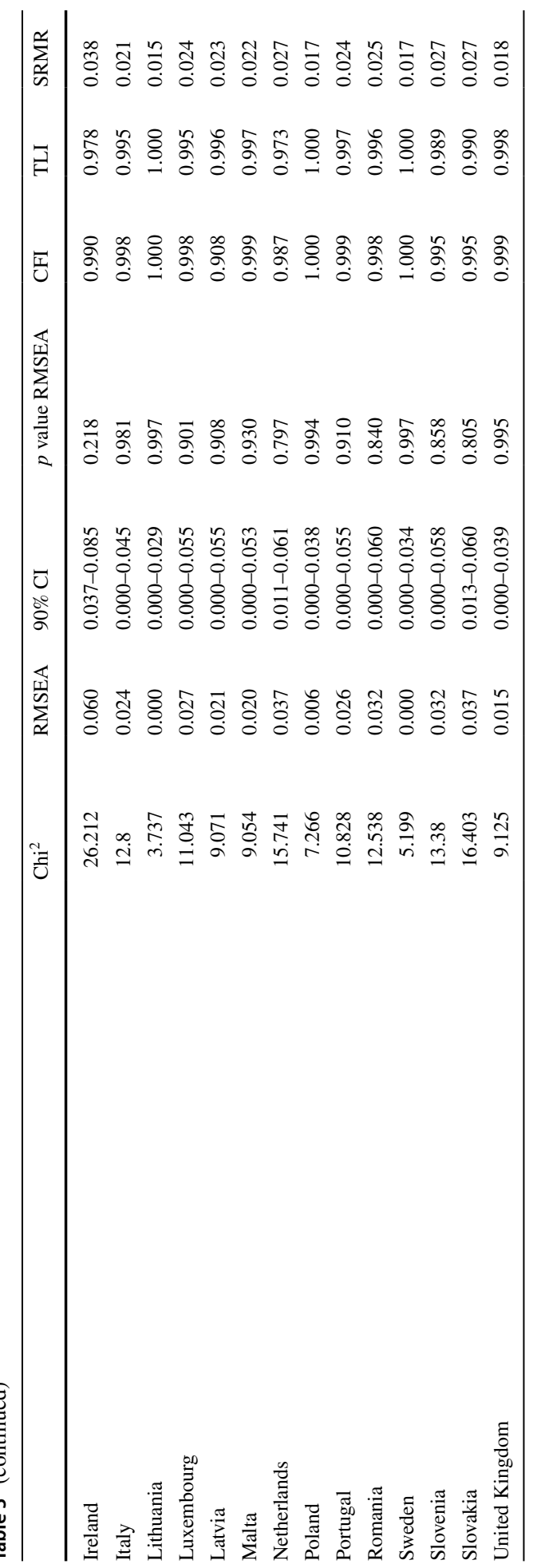




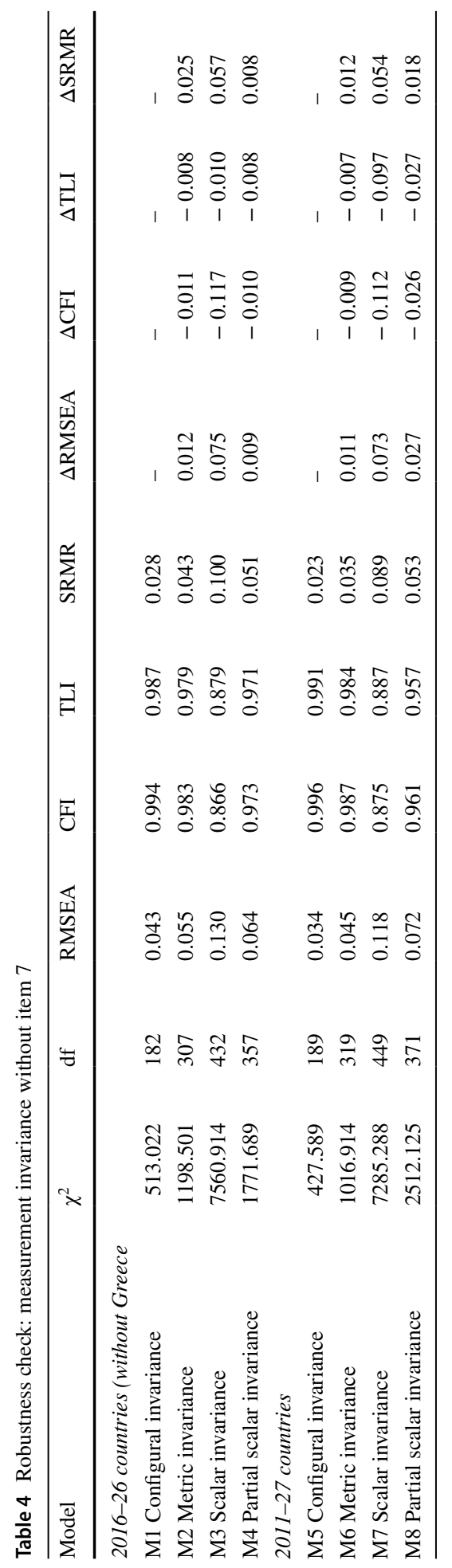




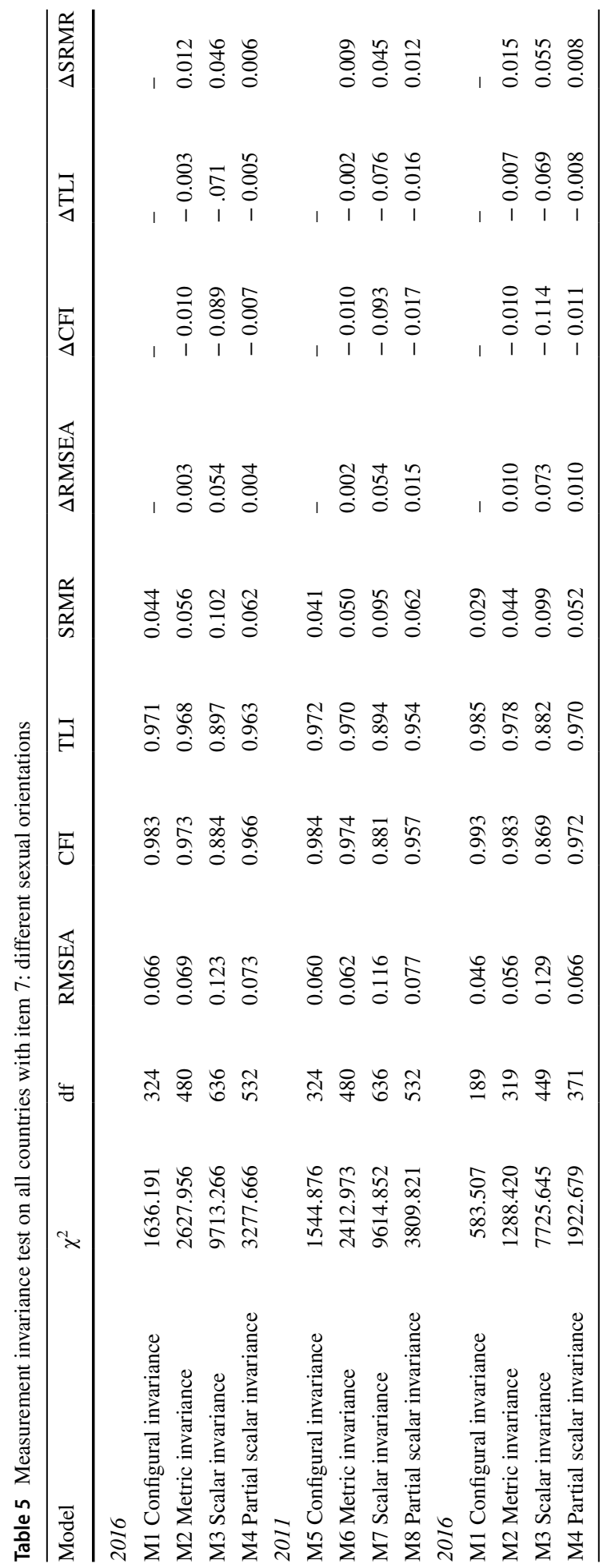


Table 6 Pearson correlation coefficients between the sum scale and latent variable generalized conflict thinking

\begin{tabular}{|c|c|c|c|}
\hline & 2016 & 2011 & 2007 \\
\hline Pooled data & 0.987 & 0.990 & 0.963 \\
\hline Austria & 0.977 & 0.993 & 0.964 \\
\hline Belgium & 0.988 & 0.991 & 0.991 \\
\hline Bulgaria & 0.989 & 0.982 & 0.974 \\
\hline Cyprus & 0.998 & 0.993 & 0.959 \\
\hline Czech Republic & 0.980 & 0.984 & 0.964 \\
\hline Germany & 0.958 & 0.962 & 0.985 \\
\hline Denmark & 0.979 & 0.986 & 0.936 \\
\hline Estonia & 0.995 & 0.984 & 0.962 \\
\hline Greece & 0.990 & 0.985 & 0.979 \\
\hline Spain & 0.993 & 0.989 & 0.989 \\
\hline Finland & 0.988 & 0.996 & 0.976 \\
\hline France & 0.994 & 0.991 & 0.991 \\
\hline Hungary & 0.987 & 0.991 & 0.962 \\
\hline Ireland & 0.987 & 0.972 & 0.991 \\
\hline Italy & 0.995 & 0.995 & 0.960 \\
\hline Lithuania & 0.981 & 0.984 & 0.943 \\
\hline Luxembourg & 0.992 & 0.997 & 0.992 \\
\hline Latvia & 0.999 & 0.994 & 0.988 \\
\hline Malta & 0.994 & 0.997 & 0.984 \\
\hline Netherlands & 0.986 & 0.989 & 0.950 \\
\hline Poland & 0.992 & 0.978 & 0.973 \\
\hline Portugal & 0.994 & 0.985 & 0.976 \\
\hline Romania & 0.991 & 0.992 & 0.961 \\
\hline Sweden & 0.974 & 0.989 & 0.949 \\
\hline Slovenia & 0.987 & 0.981 & 0.952 \\
\hline Slovakia & 0.987 & 0.978 & 0.951 \\
\hline United Kingdom & 0.999 & 0.987 & 0.984 \\
\hline
\end{tabular}


Table 7 Results of the multi-level models of socio-demographic characteristics, ethnic prejudice and political trust on generalized conflict thinking in 27 countries

\begin{tabular}{|c|c|c|c|c|}
\hline & Model 1 & Model 2 & Model 3 & Model 4 \\
\hline \multicolumn{5}{|l|}{ Indicators } \\
\hline Gender (ref. male) & $0.052 * * *(0.004)$ & $0.054 * * *(0.004)$ & $0.053 * * *(0.004)$ & $0.054 * * *(0.004)$ \\
\hline Age & $-0.001 * * *(0.000)$ & $-0.002 * * *(0.000)$ & $-0.001 * * *(0.000)$ & $-0.001 * * *(0.000)$ \\
\hline Income & $-0.014 * * *(0.002)$ & $-0.013 * * *(0.002)$ & $-0.010 * * *(0.002)$ & $-0.009 * * *(0.002)$ \\
\hline \multicolumn{5}{|l|}{ Education (ref. low) } \\
\hline Middle & $-0.003(0.005)$ & $0.003(0.005)$ & $0.001(0.005)$ & $0.005(0.005)$ \\
\hline High & $-0.016 * * *(0.006)$ & $0.002(0.006)$ & $-0.002(0.006)$ & $0.010(0.006)$ \\
\hline Ethnic prejudice & & $0.027 * * *(0.001)$ & & $0.021 * * *(0.001)$ \\
\hline Political trust & & & $-0.023 * * * *(0.001)$ & $-0.021 * * *(0.001)$ \\
\hline Intercept & $2.167 * * *(0.002)$ & $2.158 * * *(0.002)$ & $2.159 * * *(0.018)$ & $2.153 * * *(0.018)$ \\
\hline ICC & 0.089 & 0.088 & 0.090 & 0.091 \\
\hline
\end{tabular}

Standard errors in parentheses; $* \mathrm{p}<0.05 ; * * \mathrm{p}<0.01 ; * * * \mathrm{p}<0.001 ;$ total $\mathrm{N}=20,045 ;$ country $\mathrm{N}=27$

\section{Multi-level Models of Socio-Demographic Characteristics, Ethnic Prejudice and Political Trust on Generalized Conflict Thinking}

As we have established that generalized conflict thinking can be measured and used as an indicator in comparative research, our results may raise the question whether there are individual-level differences in the level of generalized perceived conflict thinking among citizens. Besides some more substantial conclusions about who perceives more societal conflict and how attitudes relate to conflict thinking, such systematic variation may also be seen as a minimal prerequisite for the external validity of our measure. Although we have no clear theoretical mechanisms that predict specific outcomes and the EQLS data contains only a limited number of interesting independent variables, below we present the results of a series of multivariate multilevel regression analyses.

We rely on the data from 2011 as this wave contains the most interesting independent variables and allows to assess the relationship of several socio-demographic characteristics, ethnic prejudice and political trust on generalized conflict thinking. The 2011 wave is the only wave that provides us with a measure for both ethnic prejudice and political trust, two political attitudes that articulate a clear preference and which contain a strong conflict element as discussed in the theoretical framework. Political trust is taken as a proxy for populist attitudes, as the data set does not contain direct measures of populist attitudes and political trust mainly reflects the anti-elitism aspect of populism that we are interested in (Geurkink et al., 2020). We use our latent construct of generalized conflict thinking as dependent variable and save the factor scores for subsequent multi-level analyses. We include socio-demographic characteristics of gender, age, income (measured in quantiles) and education (measured as three categories lowmiddle-high). Political trust is measured as a composite score of 'trust in government' and 'trust in parliament' (measured on a 0-10 continuum) where higher levels represent higher political trust. Ethnic prejudice is measured as a latent variable constructed by three items: 'immigrants are not integrated in society', 'immigrants are a strain on our welfare system' and 'our country's culture is undermined by immigrants' (measured on a $0-10$ continuum) $(\mathrm{RMSEA}=0.000, \mathrm{CFI}=1.000$ and $\mathrm{SRMR}=0.000)$. Higher levels 
represent higher levels of ethnic prejudice. For all the continuous independent variables group-mean centering is applied. We estimated multi-level models using random intercepts and fixed slopes. The results of the multi-level models are presented in Table.

Model 1 only includes socio-demographic variables. The results indicate that women, younger people, people with lower income and people who are low educated (compared to high educated people) adhere more to conflict thinking. In Model 2 and 3 we estimate the effect of ethnic prejudice (Model 2) and political trust (Model 3) on conflict thinking separately. The results indicate that people who are more ethnically prejudiced and show lower levels of political trust are more inclined to perceive societal conflict in society. Turning to the socio-demographic variables the effect of education disappears but conflict thinking is still significantly affected by gender, age and income. These effects are replicated in Model 4 where we include both ethnic prejudice and political trust as predictors for conflict thinking. These results are in line with our general expectation regarding the asymmetric relationship between preference and salience. Furthermore, the results strongly suggests that specific manifestations of conflict thinking, such as ethnic prejudice and political trust, are indeed part and parcel of a more general orientation of generalized conflict thinking, confirming the external validity of our index. The intraclass correlation coefficient (ICC) indicates that $9.1 \%$ of the variance in perceived societal conflict remains at the country level in Model 4.

Funding Funding was provided by National Science Foundation - Flanders (Grant No. G003819N).

Open Access This article is licensed under a Creative Commons Attribution 4.0 International License, which permits use, sharing, adaptation, distribution and reproduction in any medium or format, as long as you give appropriate credit to the original author(s) and the source, provide a link to the Creative Commons licence, and indicate if changes were made. The images or other third party material in this article are included in the article's Creative Commons licence, unless indicated otherwise in a credit line to the material. If material is not included in the article's Creative Commons licence and your intended use is not permitted by statutory regulation or exceeds the permitted use, you will need to obtain permission directly from the copyright holder. To view a copy of this licence, visit http://creativecommons.org/licenses/by/4.0/.

\section{References}

Altemeyer, B. (2004). Highly dominating, highly authoritarian personalities. The Journal of Social Psychology, 144(4), 421-448.

Akkerman, A., Mudde, C., \& Zaslove, A. (2014). How populist are the people? Measuring populist attitudes in voters. Comparative Political Studies, 47(9), 1324-1353

Akrami, N., Ekehammar, B., \& Bergh, R. (2011). Generalized prejudice: Common and specific components. Psychological Science, 22(1), 57-59

Baldassarri, D., \& Goldberg, A. (2014). Neither ideologues nor agnostics: Alternative voters' belief system in an age of partisan politics. American Journal of Sociology, 120(1), 45-95

Bartholomé, G., Lecheler, S., \& de Vreese, C. (2015). Manufacturing conflict? How journalists intervene in the conflict frame building process. The International Journal of Press/Politics, 20(4), 438-457

Bartholomé, G., Lecheler, S., \& de Vreese, C. (2018). Towards a typology of conflict frames: Substantiveness and interventionism in political conflict news. Journalism Studies, 19(12), 1689-1711

Bornschier, S. (2010). The new cultural divide and the two-dimensional political space in Western Europe. West European Politics, 33(3), 419-444

Bos, L., van der Brug, W., \& de Vreese, C. H. (2013). An experimental test of the impact of style and rhetoric on the perception of right-wing populist and mainstream party leaders. ActaPolitica, 48(2), 192-208

Boutyline, A. (2017). Improving the measurement of shared cultural schemas with correlational class analysis: Theory and method. Sociological Science, 4(15), 353-393 
Byrne, B. M., Shavelson, R. J., \& Muthén, B. (1989). Testing for the equivalence of factor covariance and mean structures: The issue of partial measurement invariance. Psychological Bulletin, 105(3), 456

Castanho Silva, B., Jungkunz, S., Helbling, M., \& Littvay, L. (2020). An empirical comparison of seven populist attitudes scales. Political Research Quarterly, 73(2), 409-424

Chen, F. F. (2007). Sensitivity of goodness of fit indexes to lack of measurement invariance. Structural Equation Modeling: A Multidisciplinary Journal, 14(3), 464-504

Cheung, G. W., \& Rensvold, R. B. (2002). Evaluating goodness-of-fit indexes for testing measurement invariance. Structural Equation Modeling: A Multidisciplinary Journal, 9(2), 233-255

European Commission, \& Directorate-General for Economic and Financial Affairs. (2018). The 2018 ageing report economic \& budgetary projections for the 28 EU Member States (2016-2070).

Converse, P. E. (1964). The nature of belief systems. In D. E. Apter (Ed.), Ideology and discontent. (pp. 206-261). The Free Press.

Daenekindt, S., de Koster, W., \& van der Waal, J. (2017). How people organise cultural attitudes: Cultural belief systems and the populist radical right. West European Politics, 40(4), 791-811

Dalton, R. J. (2008). The quantity and the quality of party systems: Party system polarization, its measurement, and its consequences. Comparative Political Studies, 41(7), 899-920

Davidov, E., Meuleman, B., Cieciuch, J., Schmidt, P., \& Billiet, J. (2014). Measurement equivalence in cross-national research. Annual Review of Sociology, 40(1), 55-75

Druckman, J. N., Green, D. P., Kuklinski, J. H., \& Lupia, A. (2011). Cambridge handbook of experimental political science. Cambridge University Press.

Ekehammar, B., Akrami, N., Gylje, M., \& Zakrisson, I. (2004). What matters most to prejudice: Big five personality, social dominance orientation, or right-wing authoritarianism? European Journal of Personality, 18(6), 463-482

Eurobarometer. (2019). Eurobarometer on the social acceptance of LGBTI people in the EU-2019 [Text]. European Commission-European Commission.

Forgette, R., \& Morris, J. S. (2006). High-conflict television news and public opinion. Political Research Quarterly, 59(3), 447-456

Gest, J. (2016). The new minority: White working class politics in an age of immigration and inequality. Oxford University Press.

Geurkink, B., Zaslove, A., Sluiter, R., \& Jacobs, K. (2020). Populist attitudes, political trust, and external political efficacy: Old wine in new bottles? Political Studies, 68(1), 247-267

Gidron, N., Adams, J., \& Horne, W. (2019). Toward a comparative research agenda on affective polarization in mass publics. APSA Comparative Politics Newsletter, 29, 30-36

Goldberg, A. (2011). Mapping shared understandings using relational class analysis: The case of the cultural Omnivore reexamined. American Journal of Sociology, 116(5), 1397-1436

Grande, E., Schwarzbözl, T., \& Fatke, M. (2019). Politicizing immigration in Western Europe. Journal of European Public Policy, 26(10), 1444-1463

Hameleers, M., Bos, L., \& de Vreese, C. H. (2017). "They Did It": The effects of emotionalized blame attribution in populist communication. Communication Research, 44(6), 870-900

Hatton, T. J. (2017). Public Opinion on Immigration in Europe: Preference versus Salience. IZA Discussion Papers 10838. Institute for the Study of Labor (IZA).

Hawkins, K. A., \& Kaltwasser, C. R. (2018). Introduction: The ideational approach. The ideational approach to populism: Concept, theory and analysis. (pp. 1-24). Routledge.

Hawkins, K. A., Riding, S., \& Mudde, C. (2012). Measuring Populist Attitudes (Committee on Concepts and Methods Working Paper Series). http://www.conceptsmethods.org/Files/WorkingPaper/PC_55_ Hawkins_Riding_Mudde.pdf

Hogg, M. A. (2000). Subjective uncertainty reduction through self-categorization: A motivational theory of social identity processes. European Review of Social Psychology, 11(1), 223-255

Hu, L., \& Bentler, P. M. (1999). Cutoff criteria for fit indexes in covariance structure analysis: Conventional criteria versus new alternatives. Structural Equation Modeling: A Multidisciplinary Journal, 6(1), $1-55$

Iyengar, S., Sood, G., \& Lelkes, Y. (2012). Affect, not ideology: A social identity perspective on polarization. Public Opinion Quarterly, 76(3), 405-431

Janicka, K. (2002). Dynamics of social conflict perception: Dimensions and relations. Social structure: Changes and linkages: The advanced phase of the post-communist transition in Poland, 221-30.

Jöreskog, K. G. (1971). Simultaneous factor analysis in several populations. Psychometrika, 36(4), 409-426

Kalkan, K. O., Layman, G. C., \& Uslaner, E. M. (2009). "Bands of Others"? Attitudes toward Muslims in Contemporary American Society. The Journal of Politics, 71(3), 847-862 
Kiousis, S., \& McCombs, M. (2004). Agenda-Setting effects and attitude strength: Political figures during the 1996 presidential election. Communication Research, 31(1), 36-57

Kitschelt, H. (1995). Formation of party cleavages in post-communist democracies: Theoretical propositions. Party Politics, 1(4), 447-472

Kline, R. B. (2011). Principles and practice of structural equation modeling. (3rd ed.). Guilford Press.

Krämer, B. (2014). Media populism: A conceptual clarification and some theses on its effects: Media populism. Communication Theory, 24(1), 42-60

Kriesi, H., Grande, E., Lachat, R., Dolezal, M., Bornschier, S., \& Frey, T. (2008). West European politics in the age of globalization. Cambridge University Press.

Laclau, E. (2005). On populist reason. Verso.

Lipset, S. M., \& Rokkan, S. (1967). Cleavage structures, party systems, and voter alignments: An introduction. (pp. 1-64). Free Press.

Markus, P. A., Schneider, S. K., \& Godin, A. (2016). Changes in the profile of inequality across Europe since 2005: Austerity and redistribution. European Journal of Economics and Economic Policies: Intervention, 13(3), 354-374

Mason, L. (2016). A cross-cutting calm: How social sorting drives affective polarization. Public Opinion Quarterly, 80(S1), 351-377

Meredith, W. (1993). Measurement invariance, factor analysis and factorial invariance. Psychometrika, $58(4), 525-543$

Mudde, C. (2004). The populist Zeitgeist. Government and opposition, 39(4), 541-563

Mudde, C. (2007). Populist radical right parties in Europe (Cambridge). Cambridge University Press.

Mummendey, A., Kessler, T., Klink, A., \& Mielke, R. (1999). Strategies to cope with negative social identity: Predictions by social identity theory and relative deprivation theory. Journal of Personality and Social Psychology, 76(2), 229

Norris, P., \& Inglehart, R. (2016). Trump, Brexit, and the rise of populism: Economic have-nots and cultural backlash. Harvard JFK School of Government Faculty Working Papers Series, 1-52.

OECD. (2012). Income Inequality in the European Union (OECD Economics Department Working Papers No. 952; OECD Economics Department Working Papers, Vol. 952).

Pratto, F., Sidanius, J., Stallworth, L. M., \& Malle, B. F. (1994). Social dominance orientation: A personality variable predicting social and political attitudes. Journal of Personality and Social Psychology, 67(4), 741-763

Putnick, D. L., \& Bornstein, M. H. (2016). Measurement invariance conventions and reporting: The state of the art and future directions for psychological research. Developmental Review, 41, 71-90

Reeskens, T., \& Hooghe, M. (2007). Cross-cultural measurement equivalence of generalized trust. Evidence from the European Social Survey (2002 and 2004). Social Indicators Research, 85(3), 515-532

Reiljan, A. (2020). 'Fear and loathing across party lines' (also) in Europe: Affective polarisation in European party systems. European Journal of Political Research, 59(2), 376-396.

Rohrschneider, R., \& Whitefield, S. (2009). Understanding cleavages in party systems: Issue position and issue salience in 13 post-communist democracies. Comparative Political Studies, 42(2), 280-313

Rooduijn, M. (2019). State of the field: How to study populism and adjacent topics? A plea for both more and less focus. European Journal of Political Research, 58(1), 362-372

Rooduijn, M., de Lange, S. L., \& van der Brug, W. (2014). A populist Zeitgeist ? Programmatic contagion by populist parties in Western Europe. Party Politics, 20(4), 563-575

Rosseel, Y. (2012). Lavaan: An R package for structural equation modeling and more. Version 0.5-12 BETA. Journal of Statistical Software, 48(2), 1-36

Ruggiero, C. (2014). Conflictuality in talk shows and trust in politics. A study on a university class. European Journal of Research on Education, 2(7), 1-11

Saris, W. E., \& Gallhofer, I. (2003). Report on the MTMM Experiments in the Pilot Studies and Proposals for Round 1 of the ESS. University of Amsterdam.

Schwartz, N., \& Strack, F. (1981). Manipulating salience: Causal assessment in natural settings. Personality and Social Psychology Bulletin, 7(4), 554-558

Semetko, H. A., \& Valkenburg, P. M. (2000). Framing European politics: A content analysis of press and television news. Journal of communication, 50(2), 93-109

Spruyt, B., Van Droogenbroeck, F., \& van Noord, J. (2018). Conflict thinking: Exploring the social basis of perceiving the world through the lens of social conflict. Social Science Research, 74, 16-29

Steenkamp, J.-B.E., \& Baumgartner, H. (1998). Assessing measurement invariance in cross-national consumer research. Journal of Consumer Research, 25(1), 78-90 
Steinmetz, H., Schmidt, P., Tina-Booh, A., Wieczorek, S., \& Schwartz, S. H. (2009). Testing measurement invariance using multigroup CFA: Differences between educational groups in human values measurement. Quality and Quantity, 43(4), 599-616

Turner, J. C. (1982). Towards a cognitive redefinition of the social group. Social Identity and Intergroup Relations, 1(2), 15-40

van de Schoot, R., Lugtig, P., \& Hox, J. (2012). A checklist for testing measurement invariance. European Journal of Developmental Psychology, 9(4), 486-492

Van de Vijver, F. J., Avvisati, F., Davidov, E., Eid, M., Fox, J.-P., Le Donné, N., Lek, K., Meuleman, B., Paccagnella, M., \& van de Schoot, R. (2019). Invariance analyses in large-scale studies. OECD Education Working Papers, No. 201. OECD Publishing.

Wagner, M. (2020). Affective polarization in multiparty systems. Available online in Electoral Studies.

Wlezien, C. (2005). On the salience of political issues: The problem with 'most important problem.' Electoral Studies, 24(4), 555-579

Zagórski, K. (2006). The perception of social conflicts and attitudes to democracy. International Journal of Sociology, 36(3), 3-34

Zick, A., Wolf, C., Küpper, B., Davidov, E., Schmidt, P., \& Heitmeyer, W. (2008). The syndrome of groupfocused enmity: The interrelation of prejudices tested with multiple cross-sectional and panel data. Journal of Social Issues, 64(2), 363-383

Publisher's Note Springer Nature remains neutral with regard to jurisdictional claims in published maps and institutional affiliations. 